\title{
MODERNIZACIÓN ADMINISTRATIVA Y DIFUSIÓN DE INNOVACIONES TECNOLÓGICAS EN LA ADMINISTRACIÓN LOCAL*
}

\author{
JUAN IGNACIO CRIADO \\ Universidad Complutense de Madrid
}

PALABRAS CLAVE ADICIONALES

e-Administración, World Wide Web, Nueva

Gestión Pública, Ayuntamientos, Comunidad

de Madrid

\section{ADDITIONAL KEYWORDS}

$e$-Government, World Wide Web, New Public Management, City Councils, Comunidad de Madrid

RESUMEN. La Administración Local es usuaria de las últimas tecnologías desde hace décadas. En este artículo se presenta una investigación sobre las páginas web de los ayuntamientos de la Comunidad de Madrid, teniendo en cuenta los últimos procesos de modernización administrativa en éstos y las diferencias en los niveles de desarrollo de aquéllas. Los resultados de esta investigación exploratoria muestran que, si bien las páginas web ofrecen a los ayuntamientos una serie de potencialidades relacionadas con la modernización administrativa, las administraciones locales han desarrollado de forma muy desigual este tipo de posibles beneficios. Además, a través de la creación de un índice de desarrollo web se intenta profundizar en la relación de esta variable con determinados rasgos relacionados con los ayuntamientos y su contexto institucional. En suma, este artículo aborda algunos de los puntos esenciales para entender la adopción y difusión de las innovaciones tecnológicas en la Administración Local dentro de un contexto de modernización administrativa.

* Este artículo es una versión ampliada y actualizada de una ponencia presentada en el VI Congreso Español de Ciencia Política y de la Administración, celebrado en Barcelona (18-20 de septiembre de 2003). Deseo reconocer el magnífico trabajo de David F. Barrero a lo largo de todo este proyecto y a Ana Sánchez-Sierra por su inestimable ayuda con los análisis y las ideas aportadas. Además, debo gratitud a Eduard Bonet, Eliseo López, Álvaro Martín, Mentxu Ramilo, Laura Román, Ignacio Urquizu y Yanina Welp por sus atinados comentarios, que han contribuido a mejorar versiones previas de este artículo. Obviamente, las posibles incorrecciones quedan bajo mi exclusiva responsabilidad. Este trabajo ha sido posible gracias a una beca de Formación de Personal Investigador de la Comunidad de Madrid, cofinanciada por el Fondo Social Europeo.

E-mail: jicriado@cps.ucm.es

Revista Internacional de Sociología (RIS)

Tercera Época, No 39, Septiembre-Diciembre, 2004, pp. 63-105. 
RIS

REVISTA INTERNACIONAL DE SOCIOLOGLA

№39, SEPTIEMBRE-DICIEMBRE, 200

JUAN IGNACIO CRIADO

ABSTRACT. Local administrations have used the latest technologies from decades ago. This article presents a research about the web sites of the region of Madrid's city councils, addressing the last movements through administrative modernization and the differencies between those web sites. Results of this exploratory study confirm that even if web sites offer possibilities to the city councils to develop potentialities related to the administrative modernization, local administrations have developed in a very variable way these possible benefits. Besides, using an index of web site development it is intented to get inside the relationship between this variable and some features related to the city councils and their institutional context. In sum, this article tackles with some of the critical aspects to understand the adoption and diffusion of technological innovations within the local public sector in a context of administrative modernization.

\section{INTRODUCCIÓN}

Este artículo presenta los resultados de una investigación sobre las Techologías de la Información y la Comunicación (TIC) e Internet en los ayuntamientos de la Comunidad de Madrid ${ }^{1}$. El fenómeno de la difusión de innovaciones tecnológicas dentro de los últimos procesos de modernización administrativa en las Administraciones locales se aborda mediante el análisis de una tecnología concreta, las páginas $w e b$, considerando cuáles son las razones que han provocado su difusión y uso diferenciado en el grupo de ayuntamientos objeto de estudio. La adopción de tecnologías de información y comunicación dentro del sector público local se ha incrementado de forma continua durante los últimos años, ya que la red Internet ha logrado reducir los costes de la comunicación de información entre individuos y organizaciones de una manera decisiva, aunque el rápido aumento de su popularidad a lo largo de la década de 1990 viene de la mano de uno de sus servicios asociados, la World Wide Web (WWW), es decir, las páginas web. En todo caso, no todas las organizaciones públicas están aprovechando por igual las potencialidades de este tipo de tecnología.

Numerosos autores se han acercado a las implicaciones crecientes de la tecnología web para los sistemas de gobierno y administración; sin embargo, existen todavía importantes interrogantes. Un número considerable de investigaciones ha subrayado su potencial para incrementar la participación o la calidad de las instituciones democráticas (Hague y Loader, 1999; Subirats, 2002; Wilheim, 2000); también ha despertado el interés de los estudios sobre administraciones públicas, que han analizado muchas de sus capacidades para transformar los procesos internos de trabajo (Andersen, 1999; Heeks, 1999), originar una nueva gama de servicios públicos digitales (Taylor et alia, 1996; Margetts y Dunleavy,

\footnotetext{
${ }^{1}$ Se trata de un proyecto sobre la implantación de la $e$-Administración local madrileña promovido por la Federación de Municipios de Madrid, a la que desde aquí agradezco su apoyo material y humano durante el trabajo de campo.
} 
2002) o facilitar cambios sustantivos en la gestión pública (Hood, 1995; Olías de Lima, 2002). Sin embargo, siguen existiendo lagunas en cuanto a análisis sistemáticos que analicen la difusión diferenciada de las páginas web dentro de las administraciones públicas, más allá de una enumeración de sus utilidades concretas, especialmente dentro del sector público local (Criado y Ramilo, 2003; Ramilo, 2003; Salvador, 2004).

Este artículo cuenta con un objetivo doble. Primero, se pretende una aproximación exploratoria a un objeto de estudio escasamente investigado, como son las páginas web de las administraciones locales, tratando de evaluar de manera preliminar su relación potencial con los procesos de modernización administrativa más amplios que se han iniciado en diversos contextos bajo la influencia de la Nueva Gestión Pública. Segundo, y más importante, se exploran las variaciones descubiertas en la difusión de las páginas web dentro del grupo de ayuntamientos objeto de estudio, para lo que se ha creado un índice de desarrollo web y se ha concretado un análisis estadístico de carácter descriptivo con un conjunto de variables que la literatura plantea como posibles factores que están detrás de ese fenómeno.

El artículo está informado por un marco teórico heterogéneo. Se tienen en cuenta los trabajos que han analizado los últimos procesos de modernización administrativa bajo la rúbrica de la Nueva Gestión Pública (Barzelay, 2001; Hood, 1998; Lane, 2000), se considera la literatura sobre la difusión de las innovaciones en las organizaciones (Gray, 1973; Mohr, 1969; Rogers, 1995; Walker, 1973) y las diferentes aproximaciones que han estudiado la informatización de las administraciones públicas (Frissen, 1992; Nora y Minc, 1978; Snellen, 1991; Taylor, 1992). Finalmente, se tienen en cuenta los trabajos más recientes que han abordado como objeto de estudio las páginas web dentro del sector público local (Demchak, Friis y La Porte, 2001; Horrocks y Hambley, 1998; Scavo y Yuhang, 1999).

La primera sección delimita un marco teórico sobre la modernización administrativa y las innovaciones tecnológicas en las administraciones locales, y en ella se contruyen hipótesis acerca de los factores que explican su desarrollo en este tipo de organizaciones públicas teniendo en cuenta la experiencia reciente con las páginas web. En la segunda sección se detallan los datos primarios y secundarios que han permitido la realización de este artículo y las limitaciones para el análisis derivadas de su concreción. En tercer lugar, se presenta un análisis de los datos, teniendo en cuenta las teorías e hipótesis ofrecidas previamente. En cuarto lugar, se plantea una discusión que contrasta las hipótesis formuladas y se realizan determinados comentarios que concretan los hallazgos de la investigación. Finalmente, las conclusiones profundizan en el alcance de este artículo y ofrece algunos puntos de interés para futuras investigaciones. 
R IS

REVISTA INTERNACIONAL DE SOCIOLOGIA

N` 39, SEPTIEMBRE-DICIEMBRE, 2004

JUAN IGNACIO CRIADO

\section{MARCO TEÓRICO}

La retórica de la modernización administrativa ha vuelto al primer plano en los estudios de Administración Pública durante las dos últimas décadas, aunque la atención en ese proceso a las recientes Tecnologías de la Información y la Comunicación (TIC) e Internet en sus diferentes vertientes ha sido limitada. Los últimos años han sido testigos de un intenso debate en referencia a un grupo de transformaciones en curso dentro de numerosas administraciones públicas en países de la OCDE, que se han solido integrar de manera amorfa en torno al término Nueva Gestión Pública. Estos cambios han coincidido en el tiempo y se han integrado en cierta medida con la difusión masiva en el seno de las organizaciones públicas de nuevas tecnologías de información y redes de comunicaciones, especialmente Internet, que están optimizando el intercambio de información y la generación de conocimiento, lo que ha llevado a hablar de una nueva Administración electrónica (e-Administración). Precisamente, una de las manifestaciones más conocidas de la $e$-Administración es la difusión de páginas web en el sector público, que ha abierto nuevas oportunidades a las administraciones locales para relanzar procesos de modernización administrativa gracias a su potencial para mejorar la provisión de información y la prestación de servicios públicos, así como la gestión pública. No obstante, si bien se supone que la tecnología $w e b$ encierra potenciales beneficios para las organizaciones que las adoptan, existen diferencias muy significativas en su nivel de desarrollo entre unas administraciones locales y otras, de manera que habría que preguntarse por las razones de tales variaciones. Estos son los temas que se abordan en la presente sección teniendo en cuenta una revisión de la literatura, que facilita la generación de las hipótesis que se contrastan en el análisis posterior.

\section{Una nueva gestión pública para la modernización administrativa}

El enfoque de la Nueva Gestión Pública (NGP) lleva aparejada una reacción a la llamada administración pública tradicional de carácter weberiano. La NGP es una expresión que ha sido regularmente usada por académicos y gestores para referir distintos temas, estilos y patrones de gestión pública que se han extendido en las pasadas dos décadas, sobre todo, en el Reino Unido, Australia y Nueva Zelanda. El término apareció primero en la literatura académica a principios de 1990 y rápidamente se propagó, existiendo hoy un cierto consenso académico sobre el hecho de que la NGP existe realmente, aunque no haya unanimidad en cuanto a sus contenidos concretos $\mathrm{o}$, sobre todo, su alcance en contextos burocráticos. Además, han sido prácticamente nulas las investigaciones que hayan prestado atención al papel de las tecnologías en esos procesos de cambio administrativo.

En la década de 1980 la gestión pública se convirtió en un área activa de interés en numerosos países y foros. Los países angloamericanos, otros como 
Alemania, Francia, Dinamarca o Suecia, y algunos en desarrollo se interesaron en diferente medida por la transformación de valores, instrumentos, programas de acción y marcos organizativos $\mathrm{o}$, simplemente, por la adopción de buenas prácticas gerenciales para la mejora de los servicios públicos procedentes del enfoque propuesto por la NGP (Conde, 2001). Al mismo tiempo, la OCDE estableció su Public Management Commitee and Secretariat (PUMA), confiriendo a la gestión pública la relevancia que había otorgado a otros dominios de la acción gubernamental (Barzelay, 2001). A modo de ejemplo, en la década de 1990, la gestión pública se convirtió en un asunto centrạl de la agenda presidencial de Clinton en los Estados Unidos, incluyendo el lanzamiento de la National Performance Review (1993) y la aprobación de la ley sobre el rendimiento y los resultados del Gobierno (Government Performance and Results Act, 1993) (Aberbach y Rockman, 1999).

Esa lógica de cambio en la gestión pública se originó ante la aceptación generalizada de muchas insuficiencias de la burocracia tradicional. Las carencias de la gestión de los servicios públicos siguiendo el esquema de la burocracia se hicieron patentes en un entorno de crisis económica, recorte del Estado de bienestar y expansión de la retórica liberalizadora, lo que planteó sin tapujos la necesidad de promover la lógica de los mercados en la producción y prestación de servicios públicos (Hughes, 2003). Con ello se abrió el debate sobre si las administraciones públicas eran adecuadas o suficientes para generar los outputs del sistema político, a lo que se añadió una presión en aumento para lograr una mayor calidad de los servicios en consonancia con los de las empresas privadas (Olías de Lima, 2001).

Más allá de las presiones para los cambios o el alcance de los mismos, el término NGP se ha utilizado para aglutinar numerosas herramientas (ampliamente similares) que dominaron la agenda de la reforma burocrática en muchos de los países de la OCDE desde finales de la década de 1970. De manera general, se ha relacionado la NGP con cuatro grandes tendencias administrativas (Hood, 1991: 3):

- Los intentos de frenar o invertir el crecimiento del sector público en términos de personal y gasto.

- El salto hacia la privatización y cuasi-privatización de algunas instituciones gubernamentales centrales.

- El desarrollo de una agenda más internacional, crecientemente orientada a temas generales relativos a gestión pública, diseño de políticas públicas, estilos de decisión y cooperación intergubernamental, frente a la más vieja tradición de especialidades nacionales en Administración Pública.

- El desarrollo de la automatización (particularmente en tecnologías de la información) en la producción y distribución de servicios públicos.

Esta investigación se encuadra en la última de las tendencias apuntadas, ya que se hace una aproximación a la relación creciente entre, por un lado, las tecnologías de la información y las redes de comunicaciones y, por otro, la prestación de los 
RIS

REVISTA INTERNACIONAL DE SOCIOLOGIA

No 39, SEPTIEMBRE-DICIEMBRE, 2004

JUAN IGNACIO CRIADO

servicios públicos. La amplia mayoría de los escritos vinculados con la NGP ha ignorado el fenómeno de la expansión de las TIC e Internet en el sector público. Por poner sólo un ejemplo reciente e ilustrativo, un análisis con impacto mundial sobre la reforma en la gestión pública de varios países occidentales, realizado por Pollit y Bouckaert (2000), menciona las tecnologías de la información sólo unas cuantas veces a lo largo de sus más de doscientas páginas. Muchos políticos y gestores que han seguido esta visión perciben las TIC como una herramienta neutral que no interfiere seriamente en la gestión pública; desde esta visión, la $e$-Administración no sería más que una nueva moda. Sin embargo, nuestro trabajo se intenta arrojar luz sobre uno de los retos más significativos con los que se han enfrentado las Administraciones Públicas durante los últimos años: la adopción, uso y difusión de las TIC e Internet.

Las tecnologías de la información y la comunicación e Internet en las administraciones públicas

Uno de los factores que estaría permitiendo el cambio de entorno en el que actuaban las administraciones públicas de corte burocrático es la adopción y difusión masiva de las nuevas tecnologías de información y comunicación. Los ordenadores intercomunicados gracias a redes de telecomunicaciones forman parte de la nueva tecnología que está en el núcleo de operaciones de las administraciones públicas (Hood, 1994; Margetts, 1999) y, hace no mucho tiempo, Hood (1995) hablaba de este fenómeno como uno de los subcampos dentro de las ciencias administrativas en el contexto de los cambios acaecidos en la disciplina durante las últimas décadas. A pesar del creciente reconocimiento de esa realidad, todavía existen importantes lagunas sobre el componente electrónico de las administraciones públicas, especialmente en el ámbito local, sobre todo si se tienen en cuenta los nuevos resultados derivados de la introducción de innovaciones basadas en la tecnología web (Criado y Ramilo, 2003; Dunleavy y Margetts, 2002).

Indudablemente, las tecnologías han formado parte de las administraciones públicas desde antes del siglo XX. Los telégrafos, las máquinas de escribir, los teléfonos o los ordenadores personales se integraron desde su aparición en las administraciones públicas, ya que éstas fueron adoptando el equipamiento más moderno que se encontraba disponible en cada momento, y esa difusión de las tecnologías en el sector público ha sido, y sigue siendo, un proceso político y administrativo abierto (Bellamy y Taylor, 1998). Sin embargo, sólo más recientemente algunos autores han llegado a plantear que las estructuras organizativas, descansan, en parte, en los desarrollos tecnológicos sucesivos (Mintzberg, 1999), o que las últimas tecnologías de comunicación han tenido una importancia estratégica para los cambios experimentados en la gestión de las administraciones públicas (Hughes, 2003). 
El proceso de digitalización de las telecomunicaciones, unido a numerosas innovaciones en la arquitectura informática y en los sistemas de información, se considera la base de los resultados más actuales de la relación entre las TIC e Internet y las administraciones públicas. Con la expansión de Internet se ha venido a superar el término informatización para hablar ahora de $e$-Administración, término que se puede definir de manera breve como el uso y difusión de las TIC e Internet en las administración públicas, en concreto, en el ámbito de la provisión de información, la prestación de servicios públicos y la comunicación con otras organizaciones, subrayando su papel dentro de la gestión pública (Criado, 2003) ${ }^{2}$. Lo que permite hablar de ese salto cualitativo es la existencia de una serie de características específicas en las tecnologías de información y redes de comunicaciones más recientes que, sin ánimo de ser exhaustivos, se pueden resumir en su potencial para almacenar una enorme cantidad de información, su capacidad para transferir esa información dentro y a través de unidades administrativas y entre diferentes organizaciones (y, por tanto, la posibilidad de enlazarlas) y, finalmente, su habilidad para proceder a cálculos complejos basados en esa información para convertirla en conocimiento. Estos rasgos, por ejemplo, se han concretado en nuevas formas de análisis coste-beneficio o en transacciones de servicios vía web (Heeks, 1999; Margetts y Dunleavy, 2002).

Desde un punto de vista académico, a lo largo de la segunda mitad del siglo XX las TIC se han percibido como una fuerza racionalizadora de las administraciones públicas. A pesar de esa visión común sobre la trayectoria de la relación entre las tecnologías y las organizaciones del sector público, se han producido reacciones encontradas entre los investigadores que se han acercado al estudio de este fenómeno, generalmente, entre dos grandes extremos: uno, utópico, y otro pesimista (Dunlop y Kling, 1991). Por un lado, se han desarrollado visiones utópicas centradas en los aspectos beneficiosos de las tecnologías para la sociedad y las administraciones públicas (Allcorn, 1997; Holmes, 2001, Toffler, 1990; Zuboff, 1988). Por otro lado, las perspectivas pesimistas han acentuado el potencial nocivo de las tecnologías para el sector público y la sociedad en general (Beniger, 1986; Raab, 2001; Orwell, 1954). Sin embargo, todas esas aproximaciones adolecen de un claro influjo determinista que olvida que las tecnologías se insertan en entornos organizativos determinados y dinámicas institucionales en las que los actores interactúan siguiendo determinados intereses que también afectan a su adopción y difusión.

En este trabajo se asume una visión que destaca la importancia de las últimas tecnologías de información y redes de comunicaciones en las administraciones públicas. Se plantea la necesidad de superar esas visiones inherentemente deter-

\footnotetext{
${ }^{2}$ Este fenómeno se ha equiparado al comercio electrónico dentro del sector privado (The Economist, 2000).
} 


\section{RIS}

ministas para caminar hacia una posición más equilibrada, ya que, como plantea Margetts (1999), la relación entre las tecnologías y las administraciones públicas es compleja, en tanto que aquéllas no provocan cambios en éstas de manera inevitable o autónoma; de ahí que aprehender los componentes principales de la relación entre tecnologías y sector público exige un conocimiento de la realidad administrativa, no siempre presente en los tecnológos que se han aproximado a este problema. En ese sentido, uno de los aspectos más visibles de la llamada $e$ Administración ha sido la generalización del uso de páginas web dentro del sector público y, en concreto, dentro de las administraciones locales. Sin embargo, las diferentes dimensiones desde las que se puede analizar este fenómeno se han desarrollado empíricamente de forma limitada, quizá por su propia novedad y la carencia de datos disponibles.

\section{Las páginas web}

Las páginas web suponen un nuevo objeto de interés para las administraciones públicas. En el ámbito concreto de las administraciones locales se ha ido adoptando un cierto nivel de innovaciones en lo que respecta al desarrollo de la tecnología web, sobre todo para mejorar la prestación de servicios públicos y la información que se ofrece a los ciudadanos. Aunque existe un cierto escepticismo sobre los resultados alcanzados, menos de diez años después de la aparición de las primeras páginas web gubernamentales no se puede dejar de reconocer la importancia de este tipo de tecnología, al menos como un nuevo canal de relación con los ciudadanos a través de Internet. Las primeras evaluaciones sobre los contenidos disponibles en las páginas web de las administraciones locales han puesto de relieve la enorme variedad de aproximaciones y las diferencias en cuanto a su desarrollo y, por tanto, el tipo de beneficios esperados, lo que supone la necesidad de estudiar con mayor detalle este fenómeno.

En principio, la página web no es más que uno de los servicios ofrecidos a través de Internet. Desde un plano técnico, las páginas web componen un entorno gráfico basado en el concepto de hipertexto que opera dentro de Internet, apoyando presentaciones multimedia para transmitir sonido, texto, vídeo y datos, entre diferentes ordenadores con una interfaz amigable (Berners-Lee, 1999). Por su parte, los browsers o navegadores (tales como Opera, Mozilla, Navigator, Explorer, etc.) son piezas de software que permiten a los usuarios el acceso a la información incorporada en las páginas web a través de Internet. Sin embargo, la importancia de la web procede del hecho de que es el servicio que ha permitido la socialización definitiva de Internet desde mediados de la década de 1990, ya que desde su origen con el nombre de ARPANET a fines de los años 1960 era una red a la que estaban conectados, casi exclusivamente, ordenadores de investigadores, científicos, profesores universitarios y grupos libertarios (Castells, 2001). En resumen, a comienzos del siglo XXI el uso de las páginas web se ha extendido 
entre las organizaciones y las personas con una rapidez desconocida para otro tipo de tecnologías previas (Abbate, 2000).

En los últimos años se ha empezado a plantear una serie de potenciales beneficios de las páginas web para las organizaciones, en general, y las administraciones públicas, en particular. De manera sintética, las páginas web ofrecen diversas capacidades específicas para la modernización de las administraciones locales, sobre todo gracias a su potencial para distribuir información relativa a los asuntos locales de manera más barata y para prestar servicios públicos electrónicos de manera constante. Esto supone una clara incidencia en la generación y distribución de conocimiento potencialmente disponible para los ciudadanos y las empresas sobre los temas de su interés en el ámbito municipal, debido a la facilidad de acceso de las páginas $w e b$, su disponibilidad permanente y su presentación visualmente atractiva y comprensible.

Teniendo en cuenta de forma exclusiva esas potencialidades para la provisión de información y la prestación de servicios públicos, se ha tendido a clasificar las páginas web de las administraciones locales en varios niveles de desarrollo. Diferentes estudios e informes han planteado rankings de las páginas web siguiendo unas dimensiones de análisis e indicadores concretos de medida, mediante un análisis específico de sus contenidos, a veces de forma incompleta, y normalmente desde el ámbito de la consultoría (Cap Gemini-Ernst\&Young, 2003; Fundación Retevisión, 2004; The Economist Intelligence Unit - IBM, 2003). Aunque estas aproximaciones no están libres de limitaciones, implican ciertas posibilidades para el análisis sistemático y comparado de esta nueva realidad dentro del entorno concreto de las administraciones locales, como han puesto de relieve determinados estudios académicos (Criado y Ramilo, 2001b; Criado y Ramilo, 2003; La Porte, Demchak y de Jong, 2002). De hecho, se han solido plantear varios estadios de desarrollo y, aunque en general no suelen aparecer de manera pura en la realidad, la mayoría de las páginas web puede identificarse de manera específica con las características generales de alguno de ellos, pese a que no se pueden entender desde una perspectiva meramente lineal o incremental.

La aproximación anterior deja entrever una paradoja: si como se ha planteado de manera preliminar las páginas web suponen potenciales beneficios para las administraciones locales que las adoptan, con unos costes relativamente reducidos y un alto nivel de visibilidad de cara a los ciudadanos, habría que preguntarse por qué el desarrollo de este tipo de tecnología muestra diferencias tan sustantivas entre unas administraciones locales y otras, como han puesto de relieve las primeras evaluaciones realizadas. Los estudios planteados hasta el momento se han solido centrar en clasificaciones, sin embargo, son muchas menos las investigaciones que se hayan preguntado qué hay detrás de esas variaciones entre unas administraciones locales y otras, si existen variables que las explican y en qué medida es posible abordar la cuestión de manera empírica. Ahora se repasan algunos planteamientos teóricos adecuados a este problema de estudio y se formulan las hipótesis de la investigación. 
RIS

REVISTA INTERNACIONAL DE SOCIOLOGIA

№ 39, SEPTIEMBRE-DICIEMBRE, 2004

\section{Teorías sobre la difusión de la tecnología web en las Administraciones locales}

Los estudios sobre la informatización de las administraciones públicas y la difusión de innovaciones tecnológicas ofrecen algunos argumentos para explicar las variaciones en el nivel de desarrollo de las páginas web en las administraciones locales, teniendo en cuenta también los escasos estudios realizados sobre este tipo de tecnología en las organizaciones públicas. Por una parte, los autores que han estudiado la informatización de las administraciones públicas destacan que la adopción de tecnologías no se hace en el vacío, sino que se insertan en un contexto institucional específico, de manera que determinadas características de su gestión moldean ese proceso y establecen una relación compleja con ellas. Por otra parte, el estudio de la adopción de innovaciones en las administraciones públicas completa esa perspectiva al tener en cuenta que las organizaciones y las tecnologías forman parte de un contexto en el que se relacionan con una serie de características del entorno que tienen incidencia en los procesos de difusión. Para completar esas dos perspectivas, se tienen en cuenta las investigaciones más recientes que han analizado la difusión de las páginas web en las administraciones locales.

Los autores que han analizado estos temas suelen sostener que las tecnologías no siguen un desarrollo autónomo y orientado a la generación de mejoras automáticas en las organizaciones. Las tecnologías son un antecedente obvio y necesario para su posterior desarrollo en las organizaciones públicas, pero de ninguna manera su presencia es una condición suficiente para su difusión o para la institucionalización de cambios dentro de aquéllas, tal y como han puesto de relieve diferentes estudios en contextos diversos (Bellamy y Taylor, 1996; Danziger y Dutton, 1977; Danziger et alia, 1982; Margetts, 1991, 1999; Peled, 2001; Perry et alia, 1992; Snellen, 1991). Las tecnologías se insertan en las organizaciones públicas dentro de un complejo institucional que tiene incidencia en su desarrollo y consolidación (Gascó, 2003), de manera que se ha llegado a apuntar que las instituciones existentes tienden a determinar las nuevas tecnologías para reproducir las reglas, rutinas, normas y relaciones de poder si esas reglas institucionales son claras y no existen alternativas en el ambiente organizativo (Fountain, 2001). Por ejemplo, se ha planteado la importancia de los órganos directivos existentes o los recursos humanos disponibles, ya que algunas de esas características institucionales tienen incidencia en la difusión de una nueva tecnología (Perry et alia, 1993).

En el caso concreto de las páginas web, se sugiere que determinados factores relacionados con la organización de las tecnologías en la gestión de las administraciones locales estarían detrás de las variaciones en su nivel de desarrollo. Recientemente, algunos estudios han confirmado que la difusión de la tecnología $w e b$ depende en cierta medida de variables como la existencia o no de una unidad o servicio central de dirección de las TIC y la involucración de diferentes unidades administrativas en el desarrollo de la tecnología, así como de la dedicación del personal encargado de su gestión (Moon, 2002). Junto a ello, se ha destacado 
que la existencia de una perspectiva estratégica de la gestión tecnológica es un factor institucional decisivo para explicar la difusión de las páginas web en los ayuntamientos, ya que implica un marco de referencia global en el que dar coherencia a esta nueva tecnología y es un síntoma de la experiencia tecnológica de la organización (Dunleavy y Margetts, 2002).

Hipótesis 1: Los rasgos de la organización de las tecnologías en la gestión del Ayuntamiento son factores explicativos del nivel de desarrollo de su página web.

Los estudios sobre las innovaciones en las organizaciones se han orientado a conocer cómo eran adoptadas, cómo se extendían en ellas y cómo eran abandonadas o se consolidaba su uso. Desde esta postura, se ha profundizado en la idea según la cual la difusión de las innovaciones tecnológicas en el sector público depende de una serie de factores que explican las variaciones demostradas en diversos estudios (Gray, 1973; Mohr, 1969; Rogers, 1995; Walker, 1969). Como ejemplo, se ha sostenido que las organizaciones de mayor tamaño tienen mayores probabilidades de adoptar y desarrollar innovaciones tecnológicas (Mansfield, 1963; Mohr, 1969). En el caso concreto de las administraciones locales, las organizaciones de mayor tamaño son las que ofrecen más servicios y responden a un mayor volumen de demanda de información, ya que la población de los municipios está íntimamente relacionada con el total de recursos disponibles por sus ayuntamientos y su capacidad organizativa. Por otra parte, la población de un municipio es un claro exponente del entorno informativo de su Ayuntamiento, que se puede definir como la magnitud y alcance de la información manejada para desarrollar sus actividades, con lo que el tamaño facilita una masa crítica que justifica la adopción y difusión de determinadas innovaciones tecnológicas atendiendo a las mayores necesidades de gestión de ese mayor de volumen información. En el caso concreto de las páginas web, éstas suponen un nuevo canal de comunicación que colabora en la gestión de una mayor cantidad de transacciones.

A los argumentos esgrimidos se une la idea de la existencia de economías de escala relacionadas con el tamaño de las administraciones locales. Cuanto mayor es la población de un municipio menor es para su Ayuntamiento el coste medio por usuario de la provisión de información, ya que el suministro de información depende, entre otras cosas, de los costes de su provisión, que son, en el caso de las páginas web y en un primer momento, bastante fijos y reducidos (Moon, 2002). No obstante, se ha demostrado que, a medida que se despliega toda la complejidad de esta tecnología y se pueden implementar todos sus potenciales beneficios, esos costes fijos se incrementan de manera considerable, lo que deriva en que sólo los ayuntamientos más grandes sean capaces de hacerles frente (Weare, Musso y Hale, 1999). En conclusión, cuanto más grandes son los ayuntamientos se enfrentan a un entorno humano más diverso, que demanda soluciones más innovadoras y, a su 
vez, suelen contar con mayor capacidad organizativa y recursos disponibles para dedicar a la adquisición y desarrollo de tecnologías más costosas.

Hipótesis 2: Existe una relación positiva entre el tamaño de los municipios y su capacidad para ser innovadores, es decir, cuanto mayor sea la población a la que sirven y mayor su capacidad organizativa se espera que los ayuntamientos dispongan de páginas web más desarrolladas.

Los autores que han trabajado sobre la difusión de las innovaciones tecnológicas en el sector público también entienden que existe una serie de características de las comunidades locales que inciden en la predisposición de los ayuntamientos a la adopción y uso de tecnologías y que pueden variar entre ciudades. La consideración del problema de la brecha digital aplicada al fenómeno de las páginas węb de las administraciones locales supone que diferentes antecedentes socio-económicos caracterizan la extensión de Internet y las TIC entre los ciudadanos y que, desde este punto de vista, éstos ejercen una demanda sobre el sector público para provocar la aplicación de nuevas tecnologías en la provisión de información y la prestación de servicios públicos, lo que pone el acento en la relación de las tecnologías basadas en Internet y las desigualdades de uso dentro de la esfera local (Norris, 2001).

El dinamismo tecnológico de una población tiene incidencia en el desarrollo de las tecnologías en su entorno de referencia y, en concreto, en las administraciones públicas más próximas, esto es, los ayuntamientos. Los grupos de usuarios más activos de Internet y las páginas web se sitúan entre los estratos de edad más jóvenes y entre los que disponen de mayores rentas (EGM-AIMC, 20043; Welp, 2004), de manera que se ha demostrado que en aquellos municipios donde predomina una población con estas características se ejerce una mayor demanda sobre sus administraciones locales para que empleen la tecnología $w e b$ como nuevo canal de comunicación con la ciudadanía (Ho, 2002).

Hipótesis 3: En municipios con una población caracterizada por la presencia de grupos de edad más joven y con mayor nivel de renta se espera que tengan ayuntamientos con páginas web más evolucionados.

Existen dos ideas relacionadas con un entorno favorable para la difusión de las páginas web en las Administraciones locales. En primer lugar, se supone que existe una curva ascendente de aprendizaje que ejemplifica un proceso de experimentación de soluciones cada vez más desarrolladas a medida que se adquiere mayor experiencia con una tecnología concreta (Danziger et alia, 1982; Guthrie y Dutton, 1992).

\footnotetext{
${ }^{3}$ Consultar la web del Estudio General de Medios y la Asociación para la Investigación de los Medios de Comunicación: http://www.aimc.es.
} 
Desde una perspectiva neoinstitucionalista, este fenómeno se ha asociado a los conceptos de inercia (path dependence) y de rendimientos crecientes (increasing returns). Por una parte, cuanto más se adopta una tecnología, se mejora más y mayores son los resultados derivados de su uso, lo que lleva a que cuando la adopción de una tecnología se acumula, la elección en torno a ella se convierte en estructuralmente rígida y se bloque (Powell, 1991). Por otro, las elecciones sobre la adopción y desarrollo de una nueva tecnología generan unos rendimientos crecientes derivados de la reducción de los costes de diseminar información, de la seguridad psicológica que da el uso continuado o de la coordinación de diversas actividades gracias a un tipo de tecnología (Pierson, 2000). Además, la tecnología web posee algunas características, apuntadas por Rogers (1995), que hacen que la experiencia con ella favorezca el reforzamiento de su desarrollo dentro de las organizaciones, sobre todo la facilidad de uso, la facilidad para experimentar y la facilidad para observar los resultados de la adopción.

Hipótesis 4: Cuanto mayor sea la experiencia de uso de la tecnología web y de otras tecnologías y redes previas, mayor será el desarrollo esperado de la página web del Ayuntamiento.

Las tecnologías existentes presentan una serie de oportunidades que moldean las tecnologías del futuro en el seno de las organizaciones. La experiencia en el uso de tecnologías y redes facilita la generación de modelos mentales que pueden ofrecer soluciones con capacidad para superar los dilemas asociados al desarrollo de nuevas tecnologías (Northrop et alia, 1990; Perry et alia, 1993), ya que la incertidumbre organizativa asociada a su expansión disminuye si es posible utilizar la experiencia con otras tecnologías previas o si son compatibles con las existentes, en tanto que distorsionan en menor medida los patrones de trabajo consolidados (Danziger y Dutton, 1977; King y Kraemer, 1991). En este sentido, determinados estudios han demostrado una alta compatibilidad de las páginas web con otras tecnologías precedentes, así como su capacidad para integrar innovaciones que van apareciendo más recientemente (Scavo y Yuhang, 1999).

\section{DATOS}

El análisis que se propone en este artículo está fundamentado en un conjunto de datos procedentes de diferentes fuentes primarias y secundarias. Se presentan datos primarios de una investigación completada en abril de 2003, cuyo objetivo fue recoger de manera sistemática datos sobre la situación de la $e$-Administración en los ayuntamientos de la Comunidad de Madrid, dibujando varias dimensiones de interés dentro de un ámbito de estudio en el que existe una notable escasez 
de información, a pesar de la abundante retórica de cambio administrativo gracias a las tecnologías. La investigación incluyó, por un lado, un cuestionario respondido por los responsables de la dirección y gestión de las tecnologías en los ayuntamientos analizados $\mathrm{y}$, por otro, un análisis sistemático de sus páginas $w e b$ oficiales. Para completar los datos se recurrió a otras fuentes de carácter secundario (sobre todo estadísticas oficiales) con el fin de conocer determinadas variables socio-económicas de los municipios. La limitación de los datos disponibles plantea problemas para el análisis y las inferencias causales; sin embargo, permiten establecer algunas conclusiones exploratorias y descriptivas sobre la realidad objeto de estudio.

La muestra de municipios analizados en este artículo (33) se refiere al 39,3\% del total de los ayuntamientos de tamaño medio de la Comunidad de Madrid, es decir, los que tienen entre 2.000 y 100.000 habitantes. En realidad, los Ayuntamientos analizados suponen casi el $60 \%$ de todos los que disponen de una página $w e b$ oficial dentro de ese estrato de población (57), por lo que si bien el número de casos disponibles para el análisis no es alto, la representatividad de la muestra respecto al conjunto resulta adecuada para a los objetivos de este artículo (ver Tabla 1).

Tabla 1

Municipios de la Comunidad de Madrid entre 2.000 y 100.000 habitantes (\%)

\begin{tabular}{lccc}
\hline \multicolumn{1}{c}{ Habitantes } & \multicolumn{3}{c}{ Tamaño Muestra } \\
\hline & $\mathrm{N}$ & Aytos. con web & Total Aytos. \\
\cline { 3 - 4 } & 12 & 36,4 & 22,2 \\
\hline $2.001-10.000$ & 15 & 83,3 & 65,2 \\
$10.001-50.000$ & 6 & 100 & 85,7 \\
$50.001-100.000$ & 33 & 57,9 & 39,3 \\
TOTAL & & & \\
\hline
\end{tabular}

Fuente: Elaboración propia.

Las conclusiones de este artículo se deben limitar a administraciones locales con una capacidad institucional mínima para gestionar sus recursos tecnológicos, criterio que se ha planteado en el umbral de población de 2.000 habitantes. A partir de ese tamaño se detecta que los ayuntamientos cuentan con personal específico dedicado a la gestión de las tecnologías. En el polo opuesto, se evitó incluir a los ayuntamientos de mayor tamaño (8), dado que sus características y capacidad organizativa difieren de forma sustantiva respecto a los demás. Estos 
casos tienen menor interés desde la perspectiva agregada que se desarrolla aquí, aunque su potencial como posibles estudios de caso sea incuestionable.

Una de las dos fuentes primarias de la investigación fue un cuestionario remitido a los responsables encargados de la gestión de las TIC en sus respectivos ayuntamientos. Los ayuntamientos son las organizaciones político-administrativas que ejecutan con autonomía la gestión pública local dentro de los municipios españoles (Canales, 1997) y se encargan de la prestación de una considerable cantidad de servicios públicos (Bazaga et alia, 1998), de manera que el cuestionario fue diseñado con preguntas sobre una serie de aspectos cuantitativos de hecho y percepciones relacionadas con las TIC e Internet dentro de aquéllos ${ }^{4}$. Los destinatarios finales de los cuestionarios fueron los responsables de las áreas de Informática, Nuevas Tecnologías, Sistemas de Información, Comunicaciones, Innovación Tecnológica, etc., y sólo en algún caso fueron respondidos por cargos diferentes (como el de Agente de Desarrollo Local o el de Agente de Innovación Tecnológica). A través de esta herramienta de recogida de datos se han construido determinadas variables como la experiencia con redes y tecnologías previas y la experiencia con la página web o una serie de características de la organización de las tecnologías en la gestión de los Ayuntamientos: existencia o no de un plan de $e$-Administración, presencia o no de una unidad o servicio encargado de la dirección de las TIC, dedicación del personal de gestión de la web (diaria o esporádica), tipo de gestión de la página $w e b$ (descentralizada-centralizada) y modelo de creación de la página $w e b$ (interna o externalizada).

La otra fuente primaria de datos provino de un análisis sistemático de las páginas web oficiales de todos los ayuntamientos objeto de estudio ${ }^{5}$. A partir de la observación sistemática de las páginas web analizadas se construyó una variable cuantitativa para delimitar su desarrollo concreto mediante un índice sintético. El índice de desarrollo web está compuesto de tres dimensiones, cada una de ellas referidas a varios grupos de indicadores a los que se concedió un peso relativo diferente en función de su importancia para determinar la orientación a los ciudadanos de las páginas web (ver Tabla 2 ). Estas dimensiones de análisis se han utilizado en investigaciones previas y se fundamentan en

\footnotetext{
${ }^{4} \mathrm{Si}$ se desea conocer su contenido o ampliar cualquier otra información sobre el conjunto de la investigación, se contará con las facilidades del autor para recibir cualquier material solicitado.

${ }^{5}$ El Anexo 1 presenta todas las direcciones URL de las páginas web analizadas. Se considera oficial aquélla que el Ayuntamiento plantea como propia, excluyendo las realizadas por empresas o entidades sin ánimo de lucro sobre el municipio. En todo caso, a pesar de ser más exigentes, el hecho de que casi un $60 \%$ de ellos en toda la región haya adoptado una página web indica su importancia para las organizaciones públicas, dado que no se puede olvidar que se trata de una tecnología reciente, que cumple ahora diez años desde su creación. Los sitios web fueron confirmados a través de llamadas telefónicas a los propios responsables municipales en los casos de duda. En general, se recopilaron mediante el acceso a determinadas portales específicos sobre administraciones públi-
} 
trabajos de diversos autores sobre organizaciones públicas y privadas (Criado y Ramilo, 2001a; 2001c; 2003; La Porte, Demchak y de Jong, 2002; Musso, Weare y Hale, 2000; Nielsen, 2000; Tomsen, 2000; Salvador, 2004) (ver Anexo 2):

(1) Contenidos. Se refiere a la información y servicios que pueden encontrarse en las páginas web de las Administraciones locales. Como dimensión más importante de análisis, tiene una ponderación máxima dentro del índice sintético, ya que se trata de la razón de ser de las páginas web de los ayuntamientos. Recoge ocho grupos de indicadores que categorizan y miden la presencia de los diferentes tipos de información seleccionados y, en lo que respecta a los servicios públicos, la profundidad de la información, así como el nivel de intercambio que se ofrece a los ciudadanos por medio de este canal digital.

(2) Gestión. Está compuesta por dos grupos de indicadores que reflejan el esfuerzo realizado por los responsables de los diferentes sitios web por plantear su espacio en Internet como un ámbito más de atención del gobierno local. Teniendo presente que las páginas web se han convertido en un nuevo canal de comunicación con los ciudadanos, así como un espacio para la provisión de información y la prestación de servicios públicos, se ha medido la presencia de una serie de indicadores que informan sobre el grado en que el Ayuntamiento actualiza y mantiene su sitio en Internet.

(3) Estilo. Tiene que ver con la presentación de las páginas web ante nuestra vista y qué tipo de herramientas facilitan el acceso a sus contenidos. Las dos vertientes de la dimensión estilo tienen una clara conexión con el concepto usabilidad (usebility), entendido como todo aquello que hace más sencilla para los usuarios la navegación por las páginas web. En ese sentido, estamos ante una dimensión que refleja la preocupación de la gestión pública por la accesibilidad de la información y los servicios públicos que reciben los ciudadanos a través de Internet, sobre todo, como nuevo espacio de solicitud de prestación 0 , incluso, de provisión.

A pesar de la riqueza y variedad de los datos de la presente investigación, teniendo en cuenta factores sociales, económicos, de experiencia tecnológica y gerenciales relacionados con el desarrollo de las páginas web de las administraciones locales analizadas, no dejan de existir determinadas limitaciones (ver Anexo 3). En primer lugar, hubiera sido deseable disponer de datos directos sobre el acceso a Internet de los hogares e individuos a nivel local, así como otras variables relacionadas con una visión amplia del fenómeno brecha digital, para caracterizar con más detalle la capacidad de demanda de los ciudadanos de

cas (http://www.admiweb.org; http://www.pglocal.com), buscadores (http://www.google.com; http: //www.yahoo.es) o instituciones oficiales como el Ministerio de Administraciones Públicas (http: //www.map.es) y el Gobierno de la Comunidad de Madrid (http://www.madrid.org). 
Tabla 2.

Composición del Índice de Desarrollo Web de los Ayuntamientos

\begin{tabular}{|c|c|c|c|}
\hline Dimensiones & Descripción & Grupos de indicadores & $\begin{array}{c}\text { Orientación al } \\
\text { ciudadano + }\end{array}$ \\
\hline \multirow[t]{8}{*}{ 1. Contenidos } & \multirow{8}{*}{$\begin{array}{l}\text { Información y servicios } \\
\text { disponibles en las páginas } \\
\text { web y su nivel de interacción } \\
\text { con los ciudadanos }\end{array}$} & $\begin{array}{l}\text { Información general del } \\
\text { municipio }\end{array}$ & $* *$ \\
\hline & & $\begin{array}{l}\text { Entidades y equipamientos } \\
\text { del Ayuntamiento }\end{array}$ & $* *$ \\
\hline & & $\begin{array}{l}\text { Organización interna } \\
\text { e institucional del } \\
\text { Ayuntamiento }\end{array}$ & $* *$ \\
\hline & & Servicios personales por área & $* * * * *$ \\
\hline & & $\begin{array}{l}\text { Servicios personales } \\
\text { orientados a grupos }\end{array}$ & $* * * *$ \\
\hline & & Servicios urbanos & $* * * *$ \\
\hline & & Información relacional & $* *$ \\
\hline & & $\begin{array}{l}\text { Participación. Democracia } \\
\text { electrónica }\end{array}$ & $* * * *$ \\
\hline \multirow[t]{2}{*}{ 2. Gestión } & \multirow{2}{*}{$\begin{array}{l}\text { Herramientas que explicitan } \\
\text { la gestión y mantenimiento de } \\
\text { las páginas web }\end{array}$} & Actualización & $*$ \\
\hline & & Seguridad/Privacidad & $* *$ \\
\hline \multirow[t]{3}{*}{ 3. Estilo } & \multirow{3}{*}{$\begin{array}{l}\text { Elementos que facilitan el } \\
\text { acceso a y uso de las páginas } \\
\text { web }\end{array}$} & Usabilidad & $*$ \\
\hline & & Accesibilidad & $*$ \\
\hline & & Complejidad web & $*$ \\
\hline
\end{tabular}

+ Refleja los pesos relativos asignados a cada uno de los grupos de indicadores sobre el total del indice sintético: $* * * * *$ Muy alto ${ }^{* * * *}$ Alto ${ }^{* * *}$ Medio ${ }^{* *}$ Bajo ${ }^{*}$ Muy bajo.

Fuente: Elaboración propia.

cara a estimular a las administraciones locales en el uso de páginas $w e b^{6}$. En segundo lugar, el análisis se limita a los ayuntamientos de tamaño medio de la Comunidad de Madrid y, por tanto, los resultados no se pueden extrapolar de forma automática a otras regiones españolas u otros contextos, sin tener en cuenta las características de esta investigación.

\footnotetext{
${ }^{6}$ Agradezco los comentarios específicos de Yanina Welp en torno a esta cuestión.
} 


\section{ANÁLISIS}

Un grupo importante de ayuntamientos de la Comunidad (región) de Madrid (CM) ha adoptado una página web, si bien el nivel de desarrollo de esta tecnología varía de manera considerable entre unos y otros. Aquí se analizan algunas razones que están detrás de ese fenómeno. Una aproximación descriptiva a las páginas web muestra la existencia de tres grupos de ayuntamientos que fluctúan desde un uso limitado como mero escaparate informativo, de carácter pasivo, con limitada repercusión política u organizativa, hasta los casos más desarrollados (y escasos) en los que existe la posibilidad de completar servicios públicos electrónicos y una interacción dinámica con los ciudadanos. Esta sección analiza estadísticamente, aunque de forma descriptiva y exploratoria, algunos factores que podrían explicar ese diferente nivel de desarrollo de la tecnología web dentro de las administraciones locales analizadas, teniendo en cuenta el planteamiento teórico y las hipótesis formuladas.

\section{Aproximación general a las páginas web de los ayuntamientos madrileños}

Un análisis descriptivo y agregado de los datos procedentes del análisis sistemático de las páginas web muestra algunas conclusiones de interés para la investigación. Teniendo en cuenta las dimensiones analizadas (contenidos, gestión y estilo), se pueden clasificar las páginas web de las administraciones locales en tres niveles de desarrollo según su orientación a los ciudadanos: páginas de sentido único (predomina información), páginas de doble sentido (predomina tramitación/interacción) y páginas transaccionales (predomina transacción). De manera general, se puede decir que la mayoría de las páginas web de los ayuntamientos madrileños se sitúan dentro de los dos niveles iniciales de desarrollo, a pesar de que determinadas experiencias han completado una visión transaccional.

A pesar de la ausencia de un apoyo externo generalizado y del escaso período de tiempo que ha pasado desde el nacimiento de las páginas web, se ha detectado un uso considerable dentro de las administraciones locales madrileñas. La experiencia con las páginas web en los ayuntamientos madrileños se inserta en el patrón típico de adopción de tecnologías en las organizaciones públicas, que se asemeja a una curva en forma de S (Gray, 1973). Un número relativamente pequeño de organizaciones adopta la innovación en sus períodos iniciales, pero a medida que esa tecnología se convierte en más conocida y aceptada dentro de aquéllos, el ritmo de adopción se acelera. Luego, en cuanto una amplia mayoría de los potenciales adoptantes ha asumido la innovación, el ritmo de difusión se ralentiza (Norris, 1999). En el caso de la Comunidad de Madrid parece que se confirma ese patrón de comportamiento, de manera que hasta ahora los ayuntamientos se situarían en el momento ascendente de la curva, cuando muchos intentan aprovecharse de los beneficios planteados por 
los pioneros y pretenden aplicar las posibilidades para la mejora del servicio y la equidad.

De forma más concreta, las páginas web de los ayuntamientos de la CAM, en su mayoría, se pueden situar dentro de los dos niveles iniciales de desarrollo (páginas informativas e interactivas), aunque también existen determinadas experiencias que han desarrollado una visión transaccional en la relación con los ciudadanos. A pesar de las diferencias entre las páginas web analizadas, sus contenidos se orientan mayoritariamente hacia la provisión de información de carácter general, más que a la prestación de servicios públicos vía telemática. En efecto, predominan los contenidos genéricos acerca de aspectos como la información general del municipio o la organización interna e institucional del Ayuntamiento, cuya presencia se extiende a casi todas las páginas web, mientras que otros contenidos dentro de esta consideración más genérica, como es el caso de la información sobre las entidades y equipamientos del Ayuntamiento, dispone de unos niveles de presencia algo menores, pero que alcanzan a casi el $90 \%$ de los Ayuntamientos, sobre todo los de menor tamaño.

Por su parte, la presencia de información sobre servicios públicos ha ofrecido resultados dispares y algo menores. Dentro de esta categoría se ha comprobado el predominio de información sobre los servicios personales por áreas, aunque no se ha superado del todo la visión departamental o las divisiones por concejalías dentro de las páginas web. A su vez, los servicios urbanos también han mostrado una presencia destacada, sobre todo en determinados indicadores (urbanismo o transporte) que tienen una importancia notable en la vida local. En lo que respecta a los servicios personales orientados a grupos de personas se han encontrado en porcentajes generales mucho menores (alrededor del $40 \%$ de los casos), lo que confirma las carencias de muchos de los contenidos de las páginas web.

Junto con la presencia general de los diferentes tipos de servicios, también se ha concretado un análisis sobre los niveles de profundidad de la información y su capacidad de interacción con los ciudadanos. En primer lugar, con carácter general resulta mayor la presencia de información pasiva, que la posibilidad para el intercambio con el ciudadano, bien sea mediante la tramitación/interacción o la transacción en línea. En segundo término, dentro de la capacidad de interacción con el ciudadano se ha descubierto que la realización de transacciones en línea no está muy generalizada y los casos que se pueden considerar como páginas web transaccionales se encuentran en una fase preliminar, en tanto que la gama de servicios ofrecida resulta todavía limitada, sobre todo en lo que se refiere a la personalización y áreas de cobertura. Otro tipo de contenidos observados de manera detallada son los referidos a la información relacional. Dentro de esta categoría se ha mostrado un escaso éxito de adopción dentro de la mayoría de las páginas $w e b$, privando a los ciudadanos de una información de valor añadido sobre el entorno digital de las organizaciones vinculadas con la actividad de las 
RIS

REVISTA INTERNaCIONAL DE SOCTOLOGTA

NN 39, SEPTIEMBRE-DICIEMBRE, 2004

administraciones locales. Finalmente, los indicadores sobre participación se han encontrado en un número muy reducido de páginas, lo que confirma que muchas de las promesas, tanto positivas como negativas, asociadas a la e-Democracia local están todavía lejos de cumplirse.

De manera general, la dimensión gestión de las páginas web también presenta unos niveles de desarrollo bastante limitados dentro de los Ayuntamientos de la CAM. Los indicadores relacionados con la actualización de las páginas web son los que alcanzan unos niveles de presencia mayores; sin embargo, aquéllos que ofrecen mayores posibilidades de aproximación a los ciudadanos y retroalimentación con sus opiniones, como la explicitación de una agenda de novedades con las actividades del municipio y el acceso al responsable técnico de la página web, no alcanzan niveles tan satisfactorios, ya que no se encuentran en más del $40 \%$ de los casos analizados. Acerca de otros aspectos de la gestión web, sobre todo la presencia de indicadores sobre seguridad/privacidad, se ha confirmado que todavía están en una fase preliminar, en consonancia con su escasa capacidad de interacción o transacción.

Finalmente, los indicadores referidos a la dimensión estilo ofrecen, en general, resultados similares en cuanto a posibilidades de mejora respecto a los de las dos dimensiones analizadas. Los problemas asociados al estilo se vinculan con la falta de integración con las otras dos dimensiones, como consecuencia de la inexistencia de un diseño estrátegico de las páginas web, además del hecho de que determinadas herramientas técnicas y usos concretos no están lo suficientemente extendidos en ellas. El análisis de los indicadores de estilo de las páginas $w e b$ se ha dividido en dos bloques; usabilidad y accesibilidad. Los resultados generales sobre usabilidad permiten afirmar que, en general, los sitios en Internet de los Ayuntamientos madrileños facilitan la navegación interna a los usuarios mediante herramientas adoptadas, sin embargo, de manera desigual. Por su parte, los indicadores de accesibilidad inciden en la capacidad de recuperación física de la información dentro de las páginas web y muestran índices de presencia también desiguales, aunque existen determinados aspectos, como la facilidad de carga de la página de inicio, la optimización para navegadores o la legibilidad de los contenidos que ofrecen resultados muy satisfactorios. En todo caso, estos resultados no son suficientes para plantear algo más que una aproximación general de esta dimensión, así como las evidentes limitaciones en la relación con las otras dos anteriores.

Esta parte agregada del análisis ofrece una visión de conjunto de las páginas $w e b$ objeto de estudio y sugiere su limitada incidencia dentro de procesos de modernización administrativa más globales. Existen todavía considerables limitaciones en el desarrollo de este tipo de tecnología dentro de los ayuntamientos analizados, por lo que su repercusión en la modernización de la gestión pública local resulta, a primera vista, más que limitada. Para confirmar esa conlusión,se realizaron algunas entrevistas personales que sugieren que es muy reducido el 
número de casos en los que se haya planteado una integración del desarrollo tecnológico en los ayuntamientos con las estrategias generales de cambio organizativo, o una implicación en la transformación de la organización de los servicios públicos o la atención al ciudadano. Junto a ello, el otro aspecto que interesa aquí es la existencia de notables variaciones entre unos casos y otros, es decir, de diferencias notables en el desarrollo web detectados en los ayuntamientos, más si cabe, dentro de una población organizativa más o menos homogénea en cuanto a tamaño y geográficamente. Algunas propuestas para profundizar en esta cuestión se plantean en la segunda parte del análisis.

\section{Una explicación del desarrollo web en los ayuntamientos de la Comunidad de Madrid}

La aproximación del apartado anterior es el punto de partida de un análisis que pretende avanzar en torno a las razones que se han utilizado para explicar las diferencias en el nivel de desarrollo web dentro de las administraciones locales. El desarrollo de la tecnología web de los ayuntamientos madrileños se ha medido a través de un índice sintético que permite un análisis estadístico teniendo en cuenta la limitación de los datos disponibles y, aunque no se aplica un modelo, se pretenden establecer algunas conclusiones descriptivas y exploratorias sobre las hipótesis formuladas, teniendo en cuenta otras investigaciones previas.

En la Tabla 3 se presentan los ayuntamientos objeto de estudio teniendo en cuenta la puntuación alcanzada en el índice de desarrollo web. Una aproximación a los índices obtenidos confirma, por un lado, que las posibilidades para la mejora de los sitios web son todavía considerables, ya que en la mayoría de los casos las puntuaciones son muy limitadas debido a que muchos indicadores propuestos no estaban disponibles en el momento del análisis y, por otro, que las variaciones entre unos casos y otros resultan más que notables, de forma que el análisis posterior tiene en cuenta algunos factores vinculados a los ayuntamientos para explicar tales diferencias.

La Tabla 4 compara de forma descriptiva algunas características de la organización de las tecnologías en la gestión interna de los Ayuntamientos teniendo en cuenta el desarrollo de sus páginas web. Se observa que los Ayuntamientos que tienen un mayor índice de desarrollo de la tecnología web suelen contar con un plan general de administración electrónica, una unidad o servicio central de gestión de las TIC, un personal con dedicación diaria para la gestión de la página web y una gestión descentralizada de sus contenidos; además, la creación de las páginas web en estos casos tendió a no ser externalizada. No obstante, sólo los dos primeros factores apuntados se pueden considerar estadísticamente significativos. 
RIS

REVISTA INTERNactonal DE SOCIOLOGLA

Tabla 3.

Índice de Desarrollo Web en los Ayuntamientos

\begin{tabular}{|c|c|c|c|c|c|}
\hline Posición & $\begin{array}{c}\text { Nombre } \\
\text { Ayuntamiento }\end{array}$ & $\begin{array}{l}\text { Índice entre } \\
0-100\end{array}$ & Posición & $\begin{array}{c}\text { Nombre } \\
\text { Ayuntamiento }\end{array}$ & $\begin{array}{l}\text { Índice entre } \\
0-100\end{array}$ \\
\hline 1 & Alcobendas & 60,6 & 18 & $\begin{array}{l}\text { Mejorada del } \\
\text { Campo }\end{array}$ & 29,6 \\
\hline 2 & Coslada & 57,2 & 19 & $\begin{array}{l}\text { Torres de La } \\
\text { Alameda }\end{array}$ & 28,3 \\
\hline 3 & Pinto & 52,8 & 20 & Villalbilla & 28,1 \\
\hline 4 & $\begin{array}{l}\text { Las Rozas de } \\
\text { Madrid }\end{array}$ & 51,3 & 21 & $\begin{array}{l}\text { Villarejo de } \\
\text { Salvanés }\end{array}$ & 26,5 \\
\hline 5 & Tres Cantos & 49,6 & 22 & Guadarrama & 26,2 \\
\hline 6 & $\begin{array}{l}\text { Pozuelo de } \\
\text { Alarcón }\end{array}$ & 48,5 & 23 & Ciempozuelos & 24,7 \\
\hline 7 & Collado Villalba & 43,1 & 24 & Los Molinos & 21,4 \\
\hline 8 & $\begin{array}{l}\text { Villanueva de la } \\
\text { Cañada }\end{array}$ & 42,2 & 25 & Torrelodones & 20,9 \\
\hline 9 & Algete & 41,7 & 26 & El Escorial & 20,4 \\
\hline 10 & $\begin{array}{l}\text { San Sebastián de } \\
\text { los Reyes }\end{array}$ & 38 & 27 & Chinchón & 18,8 \\
\hline 11 & Aranjuez & 36,5 & 28 & Boadilla del Monte & 17,5 \\
\hline 12 & Valdemoro & 35,8 & 29 & $\begin{array}{l}\text { Cadalso de los } \\
\text { Vidrios }\end{array}$ & 16,7 \\
\hline 13 & $\begin{array}{l}\text { San Fernando de } \\
\text { Henares }\end{array}$ & 35 & 30 & Campo Real & 16,3 \\
\hline 14 & Majadahonda & 34,1 & 31 & Valdemorillo & 15,2 \\
\hline 15 & $\begin{array}{l}\text { San Martín de la } \\
\text { Vega }\end{array}$ & 33,1 & 32 & El Boalo & 14,2 \\
\hline 16 & $\begin{array}{l}\text { San Martín de } \\
\text { Valdeiglesias }\end{array}$ & 32,1 & 33 & $\begin{array}{l}\text { Robledo de } \\
\text { Chavela }\end{array}$ & 13,1 \\
\hline 17 & Brunete & 31 & & & \\
\hline
\end{tabular}

Fuente: elaboración propia.

Desviación típica $=13,2$. En negrita los casos por encima de la media $(32,1)$.

En segundo lugar, se ha observado el comportamiento del índice de desarrollo web junto con un grupo de variables del contexto socio-económico de los municipios y de experiencia tecnológica de los ayuntamientos a través de un análisis de regresión lineal multivariante. El análisis que se detalla en la Tabla 5 sostiene que la población de los municipios es una variable significativa estadísticamente para 
Tabla 4.

Índice de Desarrollo Web según variables de Gestión y Organización +

\begin{tabular}{lccc}
\hline \multicolumn{1}{c}{ Variables } & \multicolumn{3}{c}{ Índice de Desarrollo Web } \\
\hline & $\mathrm{N}$ & $\mathrm{Sí}$ & No \\
\cline { 2 - 4 } & 33 & $45,5(9,6)$ & $28,5(11,7)$ \\
Plan de Administración electrónica** & 33 & $38,8(12,5)$ & $29,6(12,5)$ \\
$\begin{array}{l}\text { Gestión descentralizada de la web } \\
\begin{array}{l}\text { Unidad o servicio central de gestión } \\
\text { de las TIC** }\end{array}\end{array}$ & 30 & $36,7(13,6)$ & $25,3(8,6)$ \\
$\begin{array}{l}\text { Personal con dedicación diaria a la } \\
\text { gestión web }\end{array}$ & 32 & $35,4(12,1)$ & $30,2(13,8)$ \\
Creación interna de la página web & 33 & $36,7(14,8)$ & $29,8(12,1)$ \\
\hline
\end{tabular}

+ Análisis de medias ANOVA

** Indica significación estadística al 0,05

Entre paréntesis desviación típica

explicar el mayor desarrollo de la tecnología web dentro de los Ayuntamientos, lo que corrobora los resultados de otras investigaciones previas en otros contextos en las que se demostraba que las administraciones locales de mayor tamaño son las que han adoptado más rápidamente esta tecnología (Musso, Weare y Hale, 2000) y, una vez asumida, son las que más lejos han llegado en el desarrollo de su potencial (Ho, 2002).

La Tabla 5 también muestra una significación positiva de la experiencia previa en el uso de la tecnología web dentro de los Ayuntamientos. Los resultados parecen confirmar la hipótesis de una curva ascendente de aprendizaje que estimula el desarrollo de una tecnología una vez que entra a formar parte de una organización; sin embargo, en este análisis el uso previo de otras redes y tecnologías carece de efectos significativos como predictor. Finalmente, dentro del grupo analizado también se planteaba una serie de variables socioeconómicas de las comunidades locales como posibles factores explicativos del desarrollo de las páginas web en los ayuntamientos. A pesar de que un entorno que facilita la innovación afecta en cierta medida las acciones adoptadas por los ayuntamientos para institucionalizar las tecnologías, en este caso sólo se ha observado significación en la variable unida a la presencia de población joven. 
Tabla 5.

Análisis de Regresión del Índice de Desarrollo Web

\begin{tabular}{lcccc}
\hline \multicolumn{1}{c}{ Variables } & $\begin{array}{c}\text { Beta } \\
\text { (estand.) }\end{array}$ & $\begin{array}{c}\text { Error } \\
\text { típico }\end{array}$ & $\mathbf{t}$ & (Sig.) \\
\hline Constante & & 13,936 & $-1,279$ &, 212 \\
POBLAC &, 623 &, 000 & $4,652^{* *}$ &, 000 \\
MEN34 &, 245 &, 289 & $2,460^{* *}$ &, 021 \\
RENT &,- 040 &, 000 &,- 384 &, 704 \\
EXPTIC &, 114 &, 352 &, 888 &, 382 \\
EXPWEB &, 252 &, 698 & $2,607^{* *}$ &, 015 \\
\hline
\end{tabular}

Variable dependiente: índice de desarrollo web

$\mathrm{R}^{2}=0,78$

$\mathrm{R}^{2}$ ajustada $=0,74$

$\mathrm{N}=33$

** Indica significación estadística al 0,05

\section{DISCUSIÓN}

Esta sección expone una discusión de los resultados del análisis, reconsiderando las hipótesis e incorporando determinados comentarios para ayudar a una comprensión más amplia del fenómeno objeto de estudio. Los datos disponibles limitan el alcance de las posibles inferencias causales, pero el doble análisis realizado sobre las páginas web en los ayuntamientos de la Comunidad de Madrid (CAM) permite establecer algunas conclusiones de interés para futuras investigaciones sobre las tecnologías en las administraciones locales, teniendo en cuenta los procesos de modernización administrativa en marcha. Esta sección evalúa las dos partes del análisis realizado mediante una ampliación de los planteamientos teóricos con los hallazgos de esta investigación y otros estudios previos.

\section{La tecnología web como instrumento de modernización administrativa}

En la primera parte del análisis se ha realizado una aproximación agregada a las páginas web de los ayuntamientos de la CAM. Se han planteado algunas conclusiones genéricas sobre las innovaciones tecnológicas en los procesos de modernización administrativa, así como del propio papel de la tecnología web dentro 
de ellos. La NGP (Nueva Gestión Pública) ha ofrecido una serie de herramientas para la modernización de la gestión de las administraciones públicas; sin embargo, no se ha planteado de forma clara el papel de las TIC dentro de ese esquema de reformas, y en los casos en los que se ha hecho, se ha solido sugerir desde posiciones excesivamente optimistas. Las inversiones realizadas por las Administraciones locales en tecnologías de información y redes de comunicaciones han sido millonarias durante los últimos años (Ministerio de Administraciones Públicas, $1998,1999)$, pero en la mayoría de los casos no se han obtenido muchos de los resultados esperados de su rendimiento, entre otras razones porque no ha existido una integración de los programas de modernización administrativa con una visión estratégica sobre la adopción y desarrollo de las innovaciones tecnológicas. Esta conclusión permitiría ir más allá de visiones deterministas sobre las tecnologías en el sector público, ya que en el plano concreto de las administraciones locales, las innovaciones tecnológicas dependen más de factores unidos a la gestión de entornos político-administrativos, que de su desarrollo autónomo en las organizaciones (Dunleavy y Margetts, 2002).

Por otra parte, el análisis agregado ha puesto de manifiesto que la mayoría de las páginas web de los ayuntamientos analizados se encuentra en una etapa preliminar de desarrollo. El hecho de que las páginas web de las administraciones locales españolas tengan importantes posibilidades de mejora supone que todavía queda un largo camino para poner a disposición de los ciudadanos todas las promesas en torno a la provisión de información y la prestación de servicios públicos en un nuevo entorno digital. La dirección que adoptará la difusión de la tecnología web en las administraciones locales no está del todo clara, dado que se trata de un proceso abierto sin unos resultados determinados, aunque los ayuntamientos tienen capacidad para establecer unas directrices adecuadas que marquen el rumbo a través de una visión estratégica dentro de un esquema de modernización administrativa más global. Todo ello se puede concretar, bien mediante un personal directivo que formule este tipo de proyectos teniendo presente las necesidades de mejora de la gestión pública del conjunto de la organización, bien mediante la asociación con diferentes administraciones públicas, para compartir experiencia, recursos y propuestas de mejora colectiva.

Finalmente, el análisis inicial también ha puesto de manifiesto que las diferencias entre las páginas web son considerables entre unos ayuntamientos y otros, lo cual supone una evidencia empírica que es el punto de partida de la segunda parte del análisis. Esta conclusión ya se había subrayado en otros estudios recientes, que replican con cierta periodicidad clasificaciones sobre las páginas web de los ayuntamientos españoles, aunque en esta investigación se han contrastado esos datos dentro de una población organizativa que se ha seleccionado de manera consciente para que estuviera bien definida geográficamente y fuera lo más homogénea posible. 
La difusión de páginas web en las Administraciones locales: entre la innovación y la inercia institucional

La segunda parte del análisis merece una discusión más extensa, ya que pretende profundizar en los datos disponibles del análisis estadístico y en el alcance de las inferencias.

a) Primero, se ha considerado de manera descriptiva un grupo de factores relacionados con la organización de las tecnologías en la gestión de los Ayuntamientos para analizar su relación con la tecnología web. Se ha mostrado que la integración de la página web en un plan general de e-Administración y la existencia de una unidad o servicio centralizado de gestión de las TIC en el ayuntamiento son características que suelen estar presentes en los casos más evolucionados. Esto supone que la existencia de un diseño estratégico de la gestión de las tecnologías facilita la implementación de actuaciones concretas dentro de las organizaciones y que la centralización de la información es uno de los grandes potenciales de las TIC e Internet en ellas, otorgando determinadas ventajas comparativas. Este último punto es compatible con la evidencia de que los ayuntamientos con una página web más evolucionada realizan una incorporación descentralizada de contenidos, ya que se inserta la visión de toda la organización en este nuevo medio de comunicación con los ciudadanos, integrando información y conocimiento procedente de diferentes unidades administrativas, incluso alejadas físicamente. Además, los ayuntamientos que han desarrollado más la tecnología web suelen contar con personal que tiene dedicación diaria a su gestión, lo que implica una integración de la página web en la gestión corriente del Ayuntamiento y, finalmente, construyeron la página web con su propio personal, lo que presupone una experiencia previa con tecnologías muy positiva para su desarrollo posterior. En general, se trata de algunos componentes esencialmente gerenciales dentro de organizaciones político-administrativas, lo que pone de manifiesto la vigencia de un análisis desde la realidad específica de la gestión pública (Margetts, 1999). De ahí la importancia de este tipo de estudios para las ciencias administrativas.

b) Segundo, como ya ha puesto de relieve la literatura sobre las organizaciones públicas y privadas, el tamaño representa un factor clave en la adopción y difusión de tecnologías dentro de aquéllas. En el caso concreto de las administraciones locales se pueden apuntar algunos rasgos específicos que refuerzan la importancia de esta variable y que están vinculados a la proximidad de este tipo de organizaciones con los ciudadanos y con la tecnología aquí analizada. Por un lado, el hecho de que los municipios sean más grandes hace que sus ayuntamientos interactúen con un entorno ciudadano más diverso, que suele demandar soluciones más complejas ante problemas sociales cada vez más individualizados; en este sentido, se ha apuntado que los ayuntamientos de municipios más poblados contarían con la existencia de externalidades positivas unidas a potenciales redes sociales más amplias y ciudadanos con modos de vida menos estandarizados, 
incluyendo horarios y trabajos difíciles de compatibilizar con la presencia física en los edificios del Ayuntamiento para la solicitud de información, el inicio de un trámite administrativo o la recepción de un determinado servicio (Weare, Musso y Hale, 1999). Si a ello se añade el hecho de que las distancias y los desplazamientos son más costosos en tiempo en los municipios de mayor tamaño, se puede prever que sus ayuntamientos tenderán a desarrollar soluciones cada vez más complejas tecnológicamente hablando (Guthrie y Dutton, 1992). El uso y desarrollo de aplicaciones basadas en tecnología web parece que estarían entre ellas, concretando así determinadas aspiraciones de una agenda más amplia de modernización administrativa.

Por otro lado, el tamaño de los ayuntamientos también se asocia a economías de escala a la hora de adoptar y desarrollar una tecnología. Aunque los costes de creación de una página web son relativamente limitados y fijos (en algunos municipios pequeños algún vecino ha creado el sitio en Internet de su Ayuntamiento), el problema de las economías de escala es verdaderamente crucial una vez se da el paso hacia un desarrollo web orientado a la provisión de información y servicios de valor añadido para la ciudadanía, puesto que ello requiere unos costes, tanto organizativos como de gestión y personal, que no están al alcance de todos los ayuntamientos (Horrocks y Hambley, 1998; Ramió, 2002). Este aspecto se ha puesto de relieve en la presente investigación, más si cabe teniendo en cuenta un ámbito como el español en el que predominan las organizaciones de pequeño tamaño en el ámbito público local. Dado que esta variable poblacional no se puede alterar, los ayuntamientos más pequeños que han intentado promover su modernización administrativa a través de la difusión de páginas web suelen recurrir a agrupaciones municipales $u$ otras entidades supralocales (federaciones de municipios, comarcas, diputaciones o gobiernos autonómicos) para concertar una acción conjunta (Criado, 2004; Salvador, 2004), lo que ha sucedido también en otros contextos (van der Meer y van Winden, 2003; Weare, Musso y Hale, 1999). El cuestionario aplicado puso de relieve que entre las grandes barreras que identifican los propios ayuntamientos como inhibidores de la extensión de las TIC e Internet en sus organizaciones destaca la carencia de recursos, tanto materiales como humanos. Parece que la actuación conjunta para compartir esos recursos escasos es la solución más viable para la difusión futura de la tecnología web en este tipo de organizaciones.

c) Tercero, se ha considerado que determinadas características socioeconómicas de las comunidades locales a las que sirven los ayuntamientos son variables con incidencia en su desarrollo web. Esta hipótesis procede de la evidencia de que ciudadanos con mayores recursos económicos y más jóvenes son los que acceden en mayor medida a Internet y, por tanto, pueden presionar más a sus administraciones locales para que utilicen la Red y sus servicios asociados, sobre todo las páginas web (Moon, 2002). Aunque en el análisis de esta investigación sólo se ha mostrado una débil significación estadística de las variables relacionadas con esta 
RIS

REVISTA INTERNaCIONAL DE SOCIOLOGta

№ 39, SEPTIEMBRE-DICIEMBRE, 2004

cuestión, en el futuro no debería abandonarse esta hipótesis de trabajo, ya que en algunas investigaciones recientes se ha confirmado que comunidades locales con determinadas características socioeconómicas no sólo influencian el uso privado de Internet y la WWW, sino también la propia progresividad del desarrollo de las páginas web de sus administraciones locales $(\mathrm{Ho}, 2002)$. La encuesta que ha formado parte de esta investigación también ha puesto de relieve que muchos ayuntamientos plantean la falta de demanda de sus ciudadanos como otro de los factores que frena determinados proyectos tecnológicos, que no merecen tan elevadas inversiones en función de un número de potenciales usuarios todavía pequeño. Quizá habría que vincular las acciones relacionadas con la difusión de las tecnologías en las administraciones locales con otras concretas de estimulo al acceso y uso de Internet y de las TIC para los ciudadanos, lo que promovería la demanda necesaria para justificar su oferta de atención vía web como un nuevo canal complementario al presencial y telefónico. Además, aliviaría parte de los problemas planteados por la brecha digital, incluso en las sociedades desarrolladas (Norris, 2001).

d) Cuarto, se ha argumentado la existencia de una curva ascendente de aprendizaje con la tecnología web y la experiencia previa con otras tecnologías y redes como factores explicativos del desarrollo web de los ayuntamientos. El análisis ha confirmado la relación positiva entre el desarrollo actual de las páginas web y la experiencia con este tipo de tecnología, es decir, la hipótesis de la curva ascendente de aprendizaje: en la medida en que un Ayuntamiento adquiere determinadas habilidades y se familiariza con el uso y las ventajas de una página web es más probable que desarrolle cada vez más sus potencialidades y tienda en menor medida a su abandono. Los conceptos path dependence y retornos crecientes identifican mecanismos institucionales que colaboran en la consolidación de una nueva tecnología dentro de una organización, ya que a medida que se perfecciona, mayor es el resultado derivado de su uso y, cuando esto ocurre y la adopción se acumula, se produce un auto-reforzamiento que hace cada vez más difícil explorar opciones alternativas en el entorno de referencia para realizar sus funciones (Powell, 1991). Por ello, los ayuntamientos que llevan más tiempo trabajando con una página $w e b$ son los que, por un lado, tienen mayores dificultades para abandonar este tipo de tecnología y, por otro, son los que cuentan con más probabilidades de desarrollar toda su gama de potencialidades con el paso del tiempo.

Lo anterior se relaciona con la hipótesis de la experiencia con otras tecnologías y redes previas, ya que la destreza de los ayuntamientos con ellas ofrece una serie de oportunidades que moldean la difusión de otras en el futuro. En el caso concreto de las páginas web, además de la facilidad de uso, para experimentar y observar los resultados de su adopción, investigaciones recientes han demostrado que tienen un alto potencial de complementariedad con otras tecnologías existentes, como los sistemas de información geográfica, los ordenadores portátiles o los teléfonos 
móviles (Dunleavy y Margetts, 2002). En todo caso, habría que profundizar más en procesos a nivel micro para comprender mejor cómo la experiencia previa con tecnologías consolida un entorno adecuado para el uso de las últimas innovaciones y potencia su desarrollo posterior en una organización con el objetivo de reducir la incertidumbre y los costes de aprendizaje (Brudney y Selden, 1995). Aunque los autores citados no limitan sus planteamientos al sector público, no cabe duda de que estas conclusiones ayudan a entender la persistencia institucional, que es todavía más evidente en organizaciones intensivas en conocimiento, como las administraciones locales, en las que se desencadenan estas dinámicas, unidas a procesos de producción basados en conocimiento, que facilitan la generación de rendimientos crecientes (Arthur, 1990).

\section{CONCLUSIONES}

Este artículo ha profundizado en la complejidad de la intersección entre las tecnologías de información y las redes de comunicaciones y las organizaciones públicas mediante un análisis de las páginas web en los ayuntamientos de la Comunidad de Madrid. De manera sintética, la investigación ha puesto de manifiesto que si bien las páginas web ofrecen a las administraciones locales una serie de potencialidades relacionadas con la modernización administrativa bajo algunos de los presupuestos de la Nueva Gestión Pública, aquéllas han desarrollado de forma muy desigual este tipo de posibles beneficios para la mejora de la gestión interna, la prestación de servicios públicos o la provisión de información a los ciudadanos. Ante este problema de estudio, por qué existen tales diferencias en el nivel de desarrollo de la tecnología web en las administraciones locales, se han contrastado algunas hipótesis apuntadas por la literatura sobre la difusión de las innovaciones tecnológicas y la informatización de las administraciones públicas. El análisis ha servido para avanzar sobre algunos temas clave en torno a este objeto de estudio y ha permitido abrir una discusión sobre las hipótesis y los planteamientos de la literatura más reciente que ha trabajado sobre este problema de investigación, de forma que la relevancia del artículo procede de su carácter exploratorio sobre una realidad con muchos interrogantes y como estudio con base empírica con varias esferas de interés de cara a futuras aportaciones.

El carácter localizado de la investigación en un grupo homogéneo y bien definido geográficamente de administraciones locales establece los límites y oportunidades para realizar generalizaciones derivadas de los resultados obtenidos. El análisis se ha centrado en los ayuntamientos de tamaño medio de la Comunidad de Madrid, lo que a primera vista sugiere la necesidad de tomar los resultados de este estudio con cautela. Sin embargo, el carácter de la investigación garantiza el interés de esta propuesta, ya que la selección de un grupo homogéneo de administraciones locales dentro de una región española ha permitido calibrar con mayor 
R IS

REVISTA INTERnacional DE SOCiologta

No 39, SEPTIEMBRE-DICIEMBRE, 2004

profundidad algunas variables utilizadas y que de otra manera hubieran perdido parte de su potencial para el establecimiento de conclusiones. La posibilidad de generalización de los resultados deriva de que parecen apuntar en la dirección señalada por los estudios previos en otros contextos geográficos, por lo que la agenda de trabajo en torno a esta línea de investigación implica quizá una recogida más ambiciosa de datos procedentes de contextos diversos, aunque manteniendo las pautas de los autores citados, seguidas aquí de la manera más rigurosa posible a pesar de las limitaciones.

Por otro lado, este artículo se inscribe en una larga y antigua tradición de estudios sobre las tecnologías en las administraciones públicas, aunque destaca que las páginas web suponen un nuevo reto analítico, sobre todo en el sector público local. Las administraciones locales han sido un ámbito de estudio preferente por los autores que se han interesado por las tecnologías y el sector público a lo largo de los últimos cuarenta años, sobre todo analizando la informatización, es decir, las primeras etapas de la difusión de los sistemas de información o los resultados de la implantación de los ordenadores personales en las administraciones locales a partir de los años 1960 (Danziger y Dutton, 1977; Dutton y Kraemer, 1978; Kraemer, 1971). Sin embargo, la aproximación a la $e$-Administración supone un cambio sustantivo respecto a esos estudios, ya que la naturaleza de las tecnologías ha cambiado, especialmente, como consecuencia de las nuevas posibilidades que tienen las organizaciones para desarrollar formas de comunicación con otros actores del entorno y dentro de ellas mismas, derivadas del uso de Internet y sus servicios asociados, como las páginas web. En todo caso, una de las tareas por hacer consiste en analizar el alcance de las conclusiones de los estudios seminales, para confirmar pautas de trabajo más acordes con la realidad presente y, en todo caso, aprovechar las enseñanzas todavía vigentes.

Teniendo en cuenta lo anterior, un paso decisivo en el estudio de las tecnologías y las administraciones locales consiste en descartar definitivamente las perspectivas de análisis deterministas. Este artículo ha puesto de manifiesto que las organizaciones y los individuos matizan los patrones de adopción, uso y difusión de las tecnologías y, por consiguiente, existe una interacción compleja entre ellas y el contexto político-administrativo en el que se insertan. En la línea apuntada por Margetts (2003), esto supone analizar la intersección entre las tecnologías y las administraciones públicas de una manera compleja y multidimensional, de forma que futuros estudios deberían considerar otros factores de carácter personal (existencia de $e$-campeones departamentales o un neto liderazgo político), cultural (características de los usuarios internos), político (tipo de gobierno, competitividad electoral, etc.) o gerencial (extensión de doctrinas administrativas asociadas a la Nueva Gestión Pública) para adentrarse en este objeto de estudio. En esta línea, la aportación del neoinstitucionalismo concreta la tensión entre inercia e innovación institucional que caracteriza el desarrollo de nuevas tecnologías dentro de las organizaciones públicas, en general, y las administraciones locales, en particular, y 
pone de relieve la necesidad de una adecuación con los valores, intereses, rutinas y objetivos ya existentes en el seno de las organizaciones, pero sin renunciar a las capacidades para la modernización administrativa de las innovaciones tecnológicas, en este caso las páginas web, incluso dentro de entornos burocráticos.

En suma, parece que las administraciones locales españolas han aceptado el reto que supone la incorporación de la tecnología web. A pesar de que existen muchos ayuntamientos con un nivel escaso de desarrollo de este tipo de tecnología (o que carecen de ella), no deja de ser cierto que las páginas web han socializado Internet, permiten un contacto más fluido con otros actores del entorno y facilitan herramientas para reformular la organización y la gestión de los servicios públicos. Ante el reto de las nuevas tecnologías y las páginas web, las administraciones locales han de buscar determinadas soluciones a problemas internos (liderazgo, integración departamental, reingeniería de procesos, formación, etc.) y externos (brecha digital, e-Democracia, seguridad y privacidad, relaciones público/privadas, interoperabilidad, etc.), si es que quieren responder con garantías a las demandas de nuevos canales de comunicación con la ciudadanía.

\section{REFERENCIAS BIBLIOGRÁFICAS}

ABBATE, J. (2000), Inventing the Internet, Cambridge, The MIT Press.

ABERBACH, J. D. y B.A. ROCKMAN (1999), "Reinventar el Gobiemo: problemas y perspectivas", Gestión y Análisis de Políticas Públicas, n 15, pp. 3-17.

ALLCORN, S. (1997), "Parallel virtual organizations: managing and working in the virtual place", Administration \& Society, vol. 29, $\mathrm{n}^{\circ} 4$, pp. 412-439.

ANDERSEN, K. V. (1999), "Reengineering public sector organisations using information technology", en R. Heeks, ed., Reinventing government in the information age. International practice in ITenable public sector reform, Londres, Routledge, pp. 312-330.

ARTHUR, B.W. (1994), "Increasing returns and path dependence in the economy", Ann Arbor, University of Michigan Press.

BARZELAY, M. (2001), The New Public Management. Improving Research and Policy Dialogue, Berkeley, University of California Press.

BAZAGA, I., E. CARRILlO, J. A. RAMOS, J. SOSA y M. TAMAYO (1998), El Consumo y la calidad de los servicios públicos. Estudio de caso de la ciudad de Coslada, Madrid, Consejería de Medio Ambiente y Desarrollo Regional, Comunidad de Madrid-Ayuntamiento de Coslada.

BELLAMY, Ch. (2000), "Implementing information-age government: principles, progress and paradox", Public Policy and Administration, vol. 15, $\mathrm{n}^{\circ} 1$, pp. 29-42.

BELLAMY, Ch. y J. A., TAYLOR (1998), Governing in the Information Age, Buckingham, Open University Press. 
RIS

REVISTA INTERNACIONAL DE SOCIOLOGIA

NN 39, SEPTIEMBRE-DICIEMBRE, 2004

JUAN IGNACIO CRIADO

BENIGER, J. R. (1986), The Control Revolution. Technological and economical origins of the Information Society, Cambridge, Harvard University Press.

BERNERS-LEE, T. (1999), Weaving the Web. The original design and ultimate destiny of the World Wide Web, by its inventor, Nueva York, HarperCollins.

BRUDNEY, J. L. y S.C. SELDEN (1995), "The adoption of innovation by smaller local governments: the case of computer technology", American Review of Public Administration, vol. 25, $\mathrm{n}^{0} 1$, pp. 71-86.

CANALES, J. M. (1997), "La reorientación y revitalización de los Gobiernos Locales en España", Gestión y Análisis de Politicas Públicas, $\mathrm{n}^{\circ}$ 10, pp. 67-74.

CAP GEMINI, E. y YOUNG (2003), Overall report Oct-2001 Oct-2002. On line availability of public services: how does Europe progress? Web-Based survey on electronic public services, Bruselas, Comisión Europea.

CASTELLS, M. (2001), La Galaxia Internet. Reflexiones sobre Internet, empresa y sociedad, Barcelona, Plaza \& Janés.

CONDE, C. (2001), "Los Procesos de Innovación y cambio en la gestión Pública de los Países de la OCDE", en B. Olías de Lima (coord.), La Nueva Gestión Pública, Madrid, Prentice Hall, pp. 369-395.

CRIADO, J.I. (2003), “'Retórica o Realidad? La Promoción de la e-Administración en España. UnaAproximación a la Situación en la Administración General del Estado", Prospectiva, n² 25, pp. 11-22.

(2004), "Entre Sueños Utópicos y Visiones Pesimistas. Un Análisis de la Administración Electrónica Local en España", Gestión y Política Pública, vol.13, n² 2, pp. 469-524.

CRIADO, J. I. y M.C. RAMILO (2001a), "Definiendo la e-Administración. Las páginas web de las Administraciones Públicas”, Gestión y Análisis de Politicas Públicas, nº 22, pp. 123-138.

(2001b), "e-Administración, ¿un reto o una nueva moda? Problemas y perspectivas de futuro en torno a Internet y las tecnologías de la información y la comunicación en las administraciones públicas", Revista Vasca de Administración Pública, nº 61 (1), pp. 11-43.

(2003), " $e$-Government in practice. An analysis of web site orientation to the citizens in Spanish municipalities", International Journal of Public Sector Management, vol. 16, $\mathrm{n}^{0} 3$, pp. 191-218.

CRIADO, J. I., O.E. HUGHES y J. TEICHER (2002), "e-Government and managerialism: a second revolution in public management", Ponencia presentada en el VI International Research Symposium on Public Management, 8-10 abril, Edimburgo.Disponible: http://www.ems.ed.ac.uk/ irspmvi/papers/criado-hughes-teicher22.pdf. Fecha de acceso: 7 de julio de 2003.

DANZIGER, J. N., W. H. DUTTON, R. KLING y K. L. KRAEMER (eds.) (1982), Computers and Politics. High techology in American local governments, Nueva York, Columbia University Press. 
DANZIGER, J.N., W. H. DUTTON (1977), "Computers as an innovation in American local governments”, Communications of the ACM, vol. 20, $\mathrm{n}^{\circ} 12$, pp. 945-956.

DEMCHAK, C. C., C. FRIIS y T. M. La PORTE (2001), "e-Commerce and e-Governance: mutual catalystics or separate spheres?", Ponencia presentada en el VInternational Symposium on Public Management, $\mathrm{n}^{\circ}$ 9-11 abril, Barcelona.

DUNLEAVY, P. y H. MARGETTS (2002), Government on the web 2002, London, National Audit Office.

DUTTON, W.H. (ed.) (1999), Society on the line: information politics in the digital age, Oxford, Oxford University Press.

DUTTON, W.H. y K.L. KRAEMER (1978), "Management Utilization of Computers in American Local Governments", Communications of the ACM, vol. 21, $\mathrm{n}^{\circ} 3$, pp. 206-218.

FOUNTAIN, J.E. (2001), Building the virtual state. Information technology and institutional change, Washington D. C., Brookings Institution Press.

FRISSEN, P.H.A. (1992), "Informatization in public administration: introduction", International Review of Administrative Sciences, vol. 58, pp. 307-310.

FUNDACIÓN RETEVISIÓN (2004), eEspaña 2004. Informe anual sobre el desarrollo de la sociedad de la información en España, Madrid, Fundación Retevisión.

GASCÓ, M. (2003), "New technologies and institutional change in public administration", Social Science Computer Review, vol. 21, nº 1, pp. 6-14.

GRAY, V. (1973), "Innovation in the states: a diffusion study", American Political Science Review, vol. $67, n^{\circ} 4$, pp. 1174-1185.

GUTHRIE, K. K. y W. H. DUTTON (1992), "The politics of citizen access technology: the development of public information utilities in four cities", Policy Studies Journal, vol. 20, $\mathrm{n}^{\circ} 4$, pp. 574-598.

HAGUE, B. N. y B.D. LOADER (eds.) (1999), Digital democracy. Discourse and decision making in the information age, London, Routledge.

HEEKS, R. (1999), "Reinventing government in the information age", en R. Heeks (ed.), Reinventing government in the information age. International practice in IT-enable public sector reform, Londres, Routledge.

HO, A. T. (2002), "Reinventing local governments and the e-Government initiative", Public Administration Review, vol. $62, \mathrm{n}^{\circ} 4$, pp. 434-444.

HOLMES, D. (2001), e-Gov. e-Business Strategies for Government, Londres, Nicholas Brealy Publishing.

HOOD, Ch. (1991), “A Public Management for All Seasons?", Public Administration, vol. 69, $\mathrm{n}^{\circ}$ 1, pp. 3-19. 
RIS

REVISTA INTERNaCIONAL DE SOCIOLOGIA

№ 39, SEPTIEMBRE-DICIEMBRE, 2004

JUAN IGNACIO CRIADO

(1994), Explaining Economic Policy Reversals, Buckingham, Open University Press.

(1995), "Emerging issues in public administration", Public Administration, vol. 73, $\mathrm{n}^{\circ} 2, \mathrm{pp}$. 165-183.

(1998), The Art of the State. Culture, Rhetoric and Public Management, Oxford, Oxford University Press.

HORROCKS, I. y N. HAMBLEY (1998), "The webbing of British local government", Public Money \& Management, vol. $18, \mathrm{n}^{\circ} 2$, pp. 39-44.

KING, J. L. y K.L. KRAEMER (1991), "Patterns of success in municipal information systems: lessons from US experience", Informatization and the Public Sector, vol. 1, $\mathrm{n}^{0} 1$, pp. 21-39.

KRAEMER, K. L. (1971), “A Model for Urban Information Systems”, en A.F. Westin (ed.), Information Technology in a Democracy, Cambridge, Harvard University Press.

La PORTE, T. M., Ch. C. DEMCHAK y M. de JONG (2002), "Democracy and bureaucracy in the age of the Web: empirical findings and theoretical speculations", Administration \& Society vol. $34, n^{\circ} 4$, pp. 411-446.

LANE, J. E. (2000), New Public Management, Londres, Routledge.

MANSFIELD, E. (1963), "Size of firm, market structure and innovation", Journal of Political Economy, vol. 71, pp. 556-576.

MARGETTS, H. (1991), "The Computerization of Social Security: the Way Forward or Step Backwards?", Public Administration, vol. 69, n 3, pp. 325-343.

(1995), “The automated state", Public Policy and Administration, vol. 10, $\mathrm{n}^{\circ} 3$, pp. 88-103.

(1999), Information technology in Government: Britain and America, Londres, Routledge.

(2003), "Electronic Government: Method or Madness?", Inaugural Lecture, School of Public Policy, University College of London, 13 de febrero.

MARGETTS, H. y P. DUNLEAVY (2002), Better public services through e-Government, Londres, National Audit Office.

MINISTERIO DE ADMINISTRACIONES PÚBLICAS (1998), La Informática en las Administraciones Públicas. Informe IRLA-96, Madrid, Ministerio de Administraciones Públicas - Boletín Oficial del Estado.

MINISTERIO DEADMINISTRACIONES PÚBLICAS (1999), La Informática en las Administraciones Públicas. Informe IRLA-98, Madrid, Ministerio de Administraciones Públicas - Boletín Oficial del Estado.

MINTBERG, H. (1999), La Estructuración de las organizaciones, Barcelona, Ariel. 
MOHR, L. B. (1969), "Determinants of innovation in organizations", American Political Science Review, vol. 63, $\mathrm{n}^{\circ}$ 1, pp. 111-126.

MOON, M. J. (2002), "The evolución of e-Government among municipalities: rhetoric or reality?", Public Administration Review, vol. 62, $\mathrm{n}^{\circ} 4$, pp. 424-433.

MOYA, F. (ed.), (1999), GEMA proyecto de apoyo a la mecanización de los municipios de Madrid, Madrid, Consejería de Medio Ambiente y Desarrollo Regional, Comunidad de Madrid.

MUSSO, J.A., Ch. WEARE y M. L. HALE (2000), "Designing Web technologies for local governance reform: good management or good democracy?", Political Communication, vol. 17, $\mathrm{n}^{\circ} 1$, pp. $1-19$.

NIELSEN, J. (2000), Usabilidad. Diseño de sitios Web, Madrid, Prentice Hall.

NORA, S. y A. MINC (1978), L'Informatisation de la société, París, La Documentation Française. Edición en español: La informatización de la sociedad, México, Fondo de Cultura Económica, 1980.

NORRIS, D. F. (1999), "Leading edge information technologies and their adoption: lessons from U.S. cities", en G. D. Garson (ed.), Information technology and computer applications in Public Administration: issues and trends, Hershey, Publishing Idea Group.

NORRIS, D. F. y K. L. KRAEMER (1996), "Mainframe and PC computing in American cities: myths and realities", Public Administration Review, vol. 56, $\mathrm{n}^{\circ} 6$, pp. 568-576.

NORRIS, P. (2001), Digital divide. Civic engagement, information poverty and the Internet worldwide, Cambridge, Cambridge University Press.

NORTHROP, A., K. L. KRAEMER, D. E. DUNKLE y J.L. KING (1990), "Payoffs from computerization: lessons over time", Public Administration Review, vol. 50, n 5, pp. 505-514.

OLÍAS DE LIMA, B. (2001), "La Evolución de la Gestión Pública: la Nueva Gestión Pública”, en B. Olías de Lima (coord.), La Nueva Gestión Pública, Madrid, Prentice Hall, pp. 1-31.

(2002), "Las administraciones públicas españolas: balance y perspectivas”, en J. Crespo y G. Pastor (eds.), Administraciones Públicas Españolas, Madrid, McGraw-Hill, pp. 367-393.

ORWELL, G. (1954), Nineteen-Eighty-Four, Middlessex, Penguin.

PELED, A. (2001), "Centralization or difusion? Two tales of online government", Administration \& Society, vol. $32, \mathrm{n}^{\circ} 6$, pp. 686-709.

PERRY, J.L., K.L. KRAEMER, J.L. KING y D.E. DUNKLE(1992), "The institutionalization of computing in complex organizations", Informatization and the Public Sector, vol. 2, $\mathrm{n}^{\circ} 1$, pp. 47-73.

(1993), "Motivations to innovate in public organizations", en B. Bozeman, (ed.), Public Management. The state of the art. San Francisco, Jossey-Bass, pp. 294-306. 
RIS

REVISTA INTERNACIONAL DE SOCIOLOGLA

N० 39, SEPTIEMBRE-DICIEMBRE, 2004

JUAN IGNACIO CRIADO

PIERSON, P. (2000), "Increasing Returns, Path Dependence, and the Study of Politics", American Political Science Review, vol. 94, $\mathrm{n}^{\circ} 2$, pp. 251-267.

POWELL, W.W. (1991), "Expanding the Scope of InstitutionalAnalysis", en W.W. Powell y P. J. DiMaggio (eds.), The New Institutionalism in Organizational Analysis, Chicago, University of Chicago Press.

RAAB, Ch. D. (2001), "Electronic Service Delivery in the UK. Proaction and Privacy Protection", en C. Prins (ed.) Designing E-Government. On the Crossroads of Technological Innovation and Institutional Change, The Hague, Kluwer Law International, pp. 41-62.

RAMILO, M.C.(2001), El desarrollo de la sociedad de la información en Euskadi. Una aproximación a las iniciativas para su promoción en el ámbito local, Oñati, Instituto Vasco de Administración Pública.

RAMILO, M. C. (2003), "Gobierno Electrónico en la Práctica: Experiencias de Interés en la CAPV”, Revista Vasca de Administración Pública, n 67, pp. 329-353.

RAMIÓ, C. (2002), "El papel de la e-Administración ante los retos de las administraciones públicas de América Latina: $e$-Administración y sector público en el siglo de la globalización", ponencia presentada en el VII Congreso Internacional del CLAD, 8-11 abril, Lisboa.

ROGERS, E. (1995), Diffusion of innovation, Nueva York, The Free Press.

SALVADOR, M. (2002), "Gobierno electrónico y gobiernos locales. Transformaciones integrales y nuevos modelos de relación más allá de las modas", ponencia presentada en el VII Congreso Internacional del CLAD, 8-11 octubre, Lisboa.

(2004), Els Ajuntaments de Catalunya à Internet. Un Estudi Comparat de les Pàgines Web (2000-2003), Barcelona, Universitat Pompeu Fabra.

SANCHO, D. (2003), "Gobierno electrónico y participación. Factores de éxito para su desarrollo", Reforma y Democracia, ${ }^{\circ}$ 25, pp. 202-222.

SCAVO, C. y S. YUHANG, (1999), "World Wide Web site design and use in public management", en G. D. Garson (ed.), Information technology and computer applications in Public Administration: issues and trends, Heshey, Publishing Idea Group, pp. 246-266.

SUBIRATS, J. (2002), "Los dilemas de una relación inevitable. Innovación democrática y tecnologías de la información y de la comunicación", en H. Cairo (ed.), Democracia digital. Límites y oportunidades, Madrid, Trotta, pp. 89-113.

TAYLOR, J. A. (1992), "Information networking in public administration", International Review of Administrative Sciences, vol. 58, pp. 375-389.

TAYLOR, J. A., Ch. BELLAMY, Ch. D. RAAB, W. H. DUTTON y M. PELTU (1996), "Innovation in public service delivery", en W. H. Dutton (ed.), Information and communication technologies: visions and realities, Oxford, Oxford University Press, pp. 283-301.

THE ECONOMIST INTELLIGENCE UNIT - IBM (2003), The 2003 e-Readiness Rankings, London, The Economist. 
THOMAS, J.C. y G. STREIB (2003), "The new face of government: citizen-initiated contacts in the era of e-Government", Journal of Public Administration Research and Theory, vol. 13, $\mathrm{n}^{\circ}$ 1, pp. 83-102.

TOFFLER, A. (1990), Power shift, Londres, Bantam Books.

TOMSEN, M. L., (2000), Contenidos Web. Estrategias para comercio electrónico y creación de contenidos, Madrid, Prentice Hall.

VAN DER MEER, A. y W. VAN WINDEN (2003), "E-governance in cities: a comparison of urban information and communication technology policies", Regional Studies, vol. 37, pp. 4, pp. 407-419.

WALKER, J. L. (1969), "The diffusion of innovations among the American states", American Political Science Review, vol. 63, n 3, pp. 880-899.

(1973), “Comment: problems in research on diffusion of policy innovations", American Political Science Review, vol. 67, nº 4, pp. 1186-1191.

WEARE, CH., J. A. MUSSO y M. L., HALE (1999), "Electronic democracy and the diffusion of municipal Web pages in California", Administration \& Society, vol. 31, $\mathrm{n}^{\circ} 1, \mathrm{pp} .3-27$.

WELP, Y. (2004), "Nuevas Tecnologías, Viejos Problemas. El Modelo Español de Difusión de Internet", Revista Internacional de Sociología, $\mathrm{n}^{0} 37$, pp. 77-114.

WILHELM, A. G. (2000), Democracy in the digital age: challenges to political life in cyberspace, Londres, Routledge.

ZUBOFF, Sh. (1988), In the Age of the Smart Machine. The Future of Work and Power, Oxford, Basic Books. 
ANEXO 1.

AYUNTAMIENTOS ANALIZADOS EN ESTE ESTUDIO

\begin{tabular}{|c|c|c|c|c|}
\hline & AYUNTAMIENTO & POBLACIÓN & DIRECCIÓN URL (1) & UNIDAD RESPONSABLE \\
\hline 1 & ALCOBENDAS & 95.104 & http://www.alcobendas.org & $\begin{array}{l}\text { Organización y Racionalización } \\
\text { Administrativa }\end{array}$ \\
\hline 2 & ALGETE & 16.011 & http://www.algete.org & Sistemas de Información e Informática \\
\hline 3 & ARANJUEZ & 40.928 & http://www.aranjuez.net & Delegación de Desarrollo Tecnológico \\
\hline 4 & $\begin{array}{l}\text { BOADILLA DEL } \\
\text { MONTE }\end{array}$ & 27.145 & http://www.ayto-boadillam.es & Alcaldia \\
\hline 5 & BOALO, EL & 3.810 & http://www8.madrid.org/gema/goc/023 & Secretaria \\
\hline 6 & BRUNETE & 6.216 & http://www.brunete.org & Economia y Hacienda \\
\hline 7 & $\begin{array}{l}\text { CADALSO DE LOS } \\
\text { VIDRIOS }\end{array}$ & 2.329 & http://www.cadalsodelosvidrios.org & Cultura y Educación \\
\hline 8 & CAMPO REAL & 2.977 & $\begin{array}{l}\text { http://www.pglocal.com/madrid/ } \\
\text { camporeal }\end{array}$ & (2) \\
\hline 9 & CHINCHÓN & 4.346 & http://www.ciudad-chinchon.com & $(2)$ \\
\hline 10 & CIENPOZUELOS & 15.075 & http://www.ayto-ciempozuelos.org & Régimen de Interior \\
\hline 11 & COLLADO VILLALBA & 48.885 & http://www.ayto-colladovillalba.org & Departamento de Informática \\
\hline 12 & COSLADA & 79.862 & http://www.ayto-coslada.es & $\begin{array}{l}\text { Régimen Interior - Unidad de Informátical } \\
\text { Alcaldía }\end{array}$ \\
\hline 13 & EL ESCORIAL & 11.912 & http://www.ayto-elescorial.es & Personal \\
\hline 14 & GUADARRAMA & 11.280 & http://www8.madrid.org/gema/goc/068 & Desarrollo Local \\
\hline 15 & MAJADAHONDA & 52.864 & http://www.majadahonda.org & $\begin{array}{l}\text { Régimen Interior, Nuevas Tecnologias y } \\
\text { Formación }\end{array}$ \\
\hline 16 & $\begin{array}{l}\text { MEJORADA DEL } \\
\text { CAMPO }\end{array}$ & 17.560 & http://www8.madrid.org/gema/goc/084 & Hacienda \\
\hline
\end{tabular}




\begin{tabular}{|c|c|c|c|c|}
\hline 17 & MOLINOS, LOS & 3.691 & http://www.losmolinos-madrid.com & Régimen Interior \\
\hline 18 & PINTO & 31.737 & http://www.ayto-pinto.es & Informática y Comunicaciones \\
\hline 19 & $\begin{array}{l}\text { POZUEĹO DE } \\
\text { ALARCÓN }\end{array}$ & 68.470 & http://www.ayto-pozuelo.es & Hacienda y Régimen Interior \\
\hline 20 & $\begin{array}{l}\text { ROBLEDO DE } \\
\text { CHAVELA }\end{array}$ & 2.645 & http://www.espaciorobledo.com & Hacienda \\
\hline 21 & ROZAS, LAS & $62 . .527$ & http://www.ayto-lasrozas.com & Hacienda, Patrimonio y Regimen Interior \\
\hline 22 & $\begin{array}{l}\text { SAN FERNANDO DE } \\
\text { HENARES }\end{array}$ & 36.658 & http://www.ayto-sanfernando.com & Personal y Régimen Interior \\
\hline 23 & $\begin{array}{l}\text { SAN MARTÍN DE LA } \\
\text { VEGA }\end{array}$ & 12.382 & http://www.ayto-sanmartinvega.es & Promoción Económica \\
\hline 24 & $\begin{array}{l}\text { SAN MARTÍN DE } \\
\text { VALDEIGLESIAS }\end{array}$ & 6.348 & http://www.sanmartindevaldeiglesias.org & Desarrollo Económico \\
\hline 25 & $\begin{array}{l}\text { SAN SEBASTIÁN DE } \\
\text { LOS REYES }\end{array}$ & 60.323 & http://www.ssreyes.org & Servicios Generales \\
\hline 26 & TORRELODONES & 15.916 & http://www.ayto-torrelodones.es & Hacienda - Informática \\
\hline 27 & $\begin{array}{l}\text { TORRES DE LA } \\
\text { ALAMEDA }\end{array}$ & 4.871 & http://www8.madrid.org/gema/goc/154 & Informática \\
\hline 28 & TRES CANTOS & 37.688 & http://www.tres-cantos.org & Recursos Humanos y Organización Municipal \\
\hline 29 & VALDEMORILLO & 7.111 & $\begin{array}{l}\text { http://www.ayuntamientovaldemorillo } \\
\text {.com }\end{array}$ & Informática \\
\hline 30 & VALDEMORO & 34.163 & http://www.ayto-valdemoro.net & $\begin{array}{l}\text { Regimen Interior - Departamento de Infor- } \\
\text { mática }\end{array}$ \\
\hline 31 & VILLALBILLA & 5.138 & http://www.ayto-villalbilla.org & Industria y Empleo \\
\hline 32 & $\begin{array}{l}\text { VILLANUEVA DE LA } \\
\text { CAÑADA }\end{array}$ & 12.109 & http://www.ayto-villacanada.es & Alcaldia \\
\hline 33 & $\begin{array}{l}\text { VILLAREJO DE } \\
\text { SALVANÉS }\end{array}$ & 5.871 & http://www.villarejo-de-salvanes.com & $(2)$ \\
\hline
\end{tabular}




\section{ANEXO 2. \\ INDICADORES DEL ÍNDICE DE DESARROLLO WEB}

\section{Dimensión 1. Contenidos}

1. Información General del Municipio: grupo de indicadores orientados a la realidad concreta del municipio, es decir, la categoría dentro de la dimensión contenidos que posee rasgos más genéricos.

Cla Proporciona información sobre la historia del municipio

Clb Proporciona el plano o callejero

Clc Proporciona información sobre comunicaciones y accesos

Cld Proporciona el símbolo/escudo

Cle Proporciona información socioeconómica general

Clf Proporciona información sobre monumentos y museos

Clg Proporciona información sobre restauración y alojamientos

2. Entidades y Equipamientos del Ayuntamiento: indicadores acerca de instalaciones de titularidad pública con las que cuenta el Ayuntamiento para la prestación de servicios.

C2a Proporciona información sobre instalaciones del área de cultura

C2b Proporciona información sobre instalaciones del área de educación

C2c Proporciona información sobre instalaciones del área de deportes

C2d Proporciona información sobre instalaciones del área de salud

C2e Proporciona información sobre mercados

C2f Proporciona información sobre cementerios

C2g Otros

3. Organización Interna e Institucional del Ayuntamiento: grupo de indicadores acerca de áreas de organización o actividad internas del Ayuntamiento.

C3a Ofrece información sobre presupuesto

C3b Ofrece información sobre organigrama

C3c Ofrece información sobre concejales

C3d Ofrece información sobre recursos humanos

C3e Ofrece información sobre bandos y ordenanzas

C3f Ofrece información sobre normativa

C3g Ofrece información sobre actividad consistorial

4.5.6. Servicios del Ayuntamiento: grupos de indicadores que se refieren a la información que aparece en las páginas web sobre los servicios externos que prestan los ayuntamientos de cara a atender las necesidades de los ciudadanos. Este amplio grupo se ha dividido en tres categorías que diferencian los tipos de servicios más usualmente ofrecidos por las administraciones locales españolas. Además, dentro de las tres categorías de servicios se diferencia respecto a la profundidad de la información sobre los servicios y el nivel de intercambio con el ciudadano.

4. Servicios personales por área:
C4a Censo
C4b Formación
C4c Tasas 


\author{
C4d Desarrollo económico \\ C4e Salud \\ C4f Educación \\ $\mathrm{C} 4 \mathrm{~g}$ Consumo \\ C4h Seguridad social \\ C4i Cultura \\ C4j Deportes \\ C4k Turismo \\ C4l Voluntariado \\ $\mathrm{C} 4 \mathrm{~m}$ Ocio \\ C4n Empleo
}

5. Servicios personales por grupos de personas:
C5a Infancia
C5b Jóvenes
C5c Mujeres
C5d Mayores
C5e Discapacitados
C5f Inmigrantes
C5g Otros

6. Servicios urbanos:
C6a Urbanismo
C6b Transporte
C6c Obras
C6d Limpieza
C6e Vivienda
C6f Policía
C6g Ambiente
C6h Tráfico
C6i Otros

7. Información Relacional: esta categoría muestra la capacidad de las páginas web para vincular y enlazar a los ciudadanos con otras organizaciones y personas, sobre todo, Administraciones Públicas, redes ciudadanas, agentes municipales o entes internos del Ayuntamiento con presencia en Internet.

C7a Proporciona correo electrónico de Administraciones locales

C7b Proporciona correo electrónico de Administraciones autonómicas

C7c Proporciona correo electrónico de la Administraciones central

C7d Proporciona correo electrónico de la Administración europea

C7e Proporciona correo electrónico de redes ciudadanas

C7f Proporciona correo electrónico de otros agentes municipales

C7g Proporciona correo electrónico de entes internos del Ayuntamientos

C7h Proporciona correo electrónico de otros

C7i Proporciona página web de Administraciones locales

C7j Proporciona página web de Administraciones autonómicas 
RIS

REVISTA INTERNacional DE Soctocogia

C7k Proporciona página web de la Administraciones central

C71 Proporciona página web de la Administración europea

$\mathrm{C} 7 \mathrm{~m}$ Proporciona página web de redes ciudadanas

C7n Proporciona página web de otros agentes municipales

C7ñ Proporciona página web de entes intemos del Ayuntamientos

C7o Proporciona página web de otros

8. Democracia Electrónica o e-Democracia: dentro de esta categoría se insertan una serie de indicadores sobre determinadas prácticas de Democracia electrónica que algunos Ayuntamientos están ensayando mediante sus páginas web.

C8a Dispone de foros

C8b Dispone de encuestas

C8c Dispone de chats

C8d Dispone de listas de noticias

C8e Dispone de noticias

\section{Dimensión 2. Gestión}

1. Actualización: grupo de indicadores que presentan la vertiente más dinámica de las páginas web, es decir, la manera en que los Ayuntamientos las mantienen activas, se responsabilizan de su sitio en Internet y cómo reflejan esa atención en sus propias páginas de cara al control externo que puedan hacer los usuarios.

Gla Ofrece información sobre entidad creadora de la página web

Glb Ofrece información sobre agenda

Glc Ofrece información sobre fecha última actualización

Gld Ofrece información sobre acceso al responsable técnico de la web

Gle Ofrece presentación del responsable político de la web

2. Privacidad/Seguridad: indicadores acerca de la presencia de herramientas que garantizan la relación con las administraciones locales vía web. Las administraciones públicas son un tipo de organización que cuenta con unos rasgos que las hacen netamente diferentes de las privadas, especialmente, debido a la necesidad de garantizar la seguridad y respetar la privacidad de los ciudadanos y las organizaciones que interactúan con ellas, ya que suelen requerir información y datos sensibles.

G2a Existencia de política de seguridad (estándares fijados en las transacciones con los ciudadanos, sobre todo, mediante el uso de servidores SSL o herramientas de encriptación).

G2b Existencia de política de privacidad (aparición de disclaimers o anuncios las resposanbilidades del uso de los datos de los usuarios).

\section{Dimensión 3. Estilo}

1. Usabilidad: el grupo de indicadores de usabilidad refleja la capacidad de la página web para facilitar la navegación interna. Los inidicadores asociados al concepto usabilidad se refieren a la 
presentación de los contenidos de las páginas web frente a los ojos en la pantalla del terminal de acceso.
Ela Presencia de motor de búsqueda
Elb Presencia de diagrama de posición
Elc Presencia de mapa web
Eld Número de opciones en la página de inicio
Ele Número de pantallas en la página de inicio
Elf Cantidad de texto en la página de inicio

2. Accesibilidad: la accesibilidad se refiere a instrumentos para ayudar a usuarios con diferentes características a alcanzar los contenidos que se ofrecen en una página web. La accesibilidad estudia el aspecto físico de la web y la facilidad para alcanzar la información, esto es, lo que va de ojos para afuera.

E2a Tamaño de página de inicio

E2b Optimización para navegadores

E2c Uso de idiomas diferentes al español

E2d Facilidad de acceso para discapacitados

E2e Leguaje utilizado

E2f Legibilidad general

3. Complejidad web: se refiere a una evaluación general cualitativa del sitio web teniendo en cuenta tres niveles de desarrollo: información, interacción/tramitación y transacción.

\section{Anexo 3. Resumen de las Variables}

\begin{tabular}{lll}
\hline $\begin{array}{l}\text { Nombre de } \\
\text { la variable }\end{array}$ & \multicolumn{1}{c}{ Descripción de la variable } & \multicolumn{1}{c}{ Fuente } \\
\hline POBLAC & Población total de los municipios & $\begin{array}{l}\text { Instituto Nacional de } \\
\text { Estadística (INE, 2002) }\end{array}$ \\
MEN34 & $\begin{array}{l}\text { Población menor de 34 años } \\
\text { de los municipios }\end{array}$ & $\begin{array}{l}\text { Instituto Nacional de } \\
\text { Estadística (INE, 2002) }\end{array}$ \\
RENT & Renta disponible per capita en $€$ & $\begin{array}{l}\text { Instituto de Estadística } \\
\text { de la Comunidad de } \\
\text { Madrid (IECAM, 2000) }\end{array}$ \\
& $\begin{array}{l}\text { Suma total de los años de uso en los } \\
\text { EXPTIC }\end{array}$ & $\begin{array}{l}\text { Ayuntamientos de Redes de Área local, } \\
\text { Internet e Intranet, desde 2003 }\end{array}$ \\
& $\begin{array}{l}\text { Suma total de los años de uso en los } \\
\text { Ayuntamientos de su página web, desde 2003 }\end{array}$ & Cuestionario \\
\hline
\end{tabular}

